\title{
Development of a high-resolution emission inventory and its evaluation and application through air quality modeling for Jiangsu Province, China
}

\author{
Yaduan Zhou ${ }^{1}$, Yu Zhao ${ }^{1,2}$, Pan Mao ${ }^{1}$, Qiang Zhang ${ }^{3}$, Jie Zhang ${ }^{2,4}$, Liping Qiu ${ }^{1}$, and Yang Yang ${ }^{1}$ \\ ${ }^{1}$ State Key Laboratory of Pollution Control and Resource Reuse and School of the Environment, Nanjing University, \\ 163 Xianlin Ave., Nanjing, Jiangsu 210023, China \\ ${ }^{2}$ Jiangsu Collaborative Innovation Center of Atmospheric Environment and Equipment Technology (CICAEET), \\ Nanjing University of Information Science and Technology, Jiangsu 210044, China \\ ${ }^{3}$ Ministry of Education Key Laboratory for Earth System Modeling, Center for Earth System Science, Tsinghua University, \\ Beijing 100084, China \\ ${ }^{4}$ Jiangsu Provincial Academy of Environmental Science, 176 North Jiangdong Rd., Nanjing, Jiangsu 210036, China
}

Correspondence to: Yu Zhao (yuzhao@nju.edu.cn)

Received: 29 June 2016 - Published in Atmos. Chem. Phys. Discuss.: 25 July 2016

Revised: 22 November 2016 - Accepted: 28 November 2016 - Published: 4 January 2017

\begin{abstract}
Improved emission inventories combining detailed source information are crucial for better understanding of the atmospheric chemistry and effectively making emission control policies using air quality simulation, particularly at regional or local scales. With the downscaled inventories directly applied, chemical transport models might not be able to reproduce the authentic evolution of atmospheric pollution processes at small spatial scales. Using the bottom-up approach, a high-resolution emission inventory was developed for Jiangsu China, including $\mathrm{SO}_{2}, \mathrm{NO}_{x}, \mathrm{CO}, \mathrm{NH}_{3}$, volatile organic compounds (VOCs), total suspended particulates (TSP), $\mathrm{PM}_{10}, \mathrm{PM}_{2.5}$, black carbon (BC), organic carbon (OC), and $\mathrm{CO}_{2}$. The key parameters relevant to emission estimation for over 6000 industrial sources were investigated, compiled, and revised at plant level based on various data sources and on-site surveys. As a result, the emission fractions of point sources were significantly elevated for most species. The improvement of this provincial inventory was evaluated through comparisons with other inventories at larger spatial scales, using satellite observation and air quality modeling. Compared to the downscaled Multi-resolution Emission Inventory for China (MEIC), the spatial distribution of $\mathrm{NO}_{x}$ emissions in our provincial inventory was more consistent with summer tropospheric $\mathrm{NO}_{2}$ VCDs observed from OMI, particularly for the grids with moderate emission
\end{abstract}

levels, implying the improved emission estimation for small and medium industrial plants by this work. Three inventories (national, regional, and provincial by this work) were applied in the Models-3 Community Multi-scale Air Quality (CMAQ) system for southern Jiangsu October 2012, to evaluate the model performances with different emission inputs. The best agreement between available ground observation and simulation was found when the provincial inventory was applied, indicated by the smallest normalized mean bias (NMB) and normalized mean errors (NME) for all the concerned species $\mathrm{SO}_{2}, \mathrm{NO}_{2}, \mathrm{O}_{3}$, and $\mathrm{PM}_{2.5}$. The result thus implied the advantage of improved emission inventory at local scale for high-resolution air quality modeling. Under the unfavorable meteorology in which horizontal and vertical movement of atmosphere was limited, the simulated $\mathrm{SO}_{2}$ concentrations at downtown Nanjing (the capital city of Jiangsu) using the regional or national inventories were much higher than those observed, implying that the urban emissions were overestimated when economy or population densities were applied to downscale or allocate the emissions. With more accurate spatial distribution of emissions at city level, the simulated concentrations using the provincial inventory were much closer to observation. Sensitivity analysis of $\mathrm{PM}_{2.5}$ and $\mathrm{O}_{3}$ formation was conducted using the improved provincial inventory through the "brute force" 
method. Iron and steel plants and cement plants were identified as important contributors to the $\mathrm{PM}_{2.5}$ concentrations in Nanjing. The $\mathrm{O}_{3}$ formation was VOC-limited in southern Jiangsu, and the concentrations were negatively correlated with $\mathrm{NO}_{x}$ emissions in urban areas owing to the accumulated $\mathrm{NO}_{x}$ from transportation. More evaluations are further suggested for the impacts of speciation and temporal and vertical distribution of emissions on air quality modeling at regional or local scales in China.

\section{Introduction}

With rapid development of economy and growth of energy consumption, eastern China is experiencing severe atmospheric pollution attributed to the large emissions of primary air pollutants and the subsequent formation of secondary pollution, e.g., fine particles and $\mathrm{O}_{3}$. Relatively high concentrations of surface $\mathrm{PM}_{2.5}$ were observed in eastern China based on the national monitoring network (data source: http: //106.37.208.233:20035/), and only $9.5 \%$ out of 190 cities with the measurement data reported in 2014 met the National Ambient Air Quality Standard (NAAQS), i.e., $35 \mu \mathrm{g} \mathrm{m}^{-3}$ for annual $\mathrm{PM}_{2.5}$ concentration (MEP, 2012). To deal with the serious problem of air pollution, series of measures have been conducted to reduce the pollutant emissions and to improve the air quality across the country. For example, the National Air Pollution Prevention Action Plan, issued in 2013, required strict emission controls on both industry and transportation sectors, and aimed to achieve a 25, 20, and $15 \%$ reduction of annual $\mathrm{PM}_{2.5}$ concentration for BeijingTianjin-Hebei (JJJ), the Yangtze River Delta (YRD), and the Pearl River Delta (PRD) regions, respectively, from 2012 to 2017. Given the non-linear response of ambient concentrations to emissions, chemical transport modeling (CTM) has been widely applied to study the mechanisms of complex pollution processes and the impacts of emission abatement (Zhang et al., 2006; Streets et al., 2007; B. Zhao et al., 2013; Zhang et al., 2012). As the key input of CTM, therefore, improved emission inventories, particularly at regional or local scales, become important for scientific air quality simulation and effective policy-making.

Progress has been increasingly achieved in emission inventory studies for China. Compared to earlier national emission inventories including those for Transport and Chemical Evolution over the Pacific Mission (TRACE-P, Streets et al., 2003), Intercontinental Chemical Transport ExperimentPhase B (INTEX-B, Zhang et al., 2009), and Regional Emission inventory in Asia (REAS, Ohara et al., 2007; Kurokawa et al., 2013), Tsinghua University developed the Multiresolution Emission Inventory for China (MEIC, http://www. meicmodel.org/), in which the information of large power plants and cement factories was investigated and the uncertainties of emission estimation for those typical sources were reduced (Wang et al., 2014). Besides, high-resolution emission inventories at regional and city scales were gradually established in the developed regions JJJ, YRD, and PRD, attributed to better data support and a stronger need to combat air pollution (Zheng et al., 2009; S. X. Wang et al., 2010; Huang et al., 2011; B. Zhao et al., 2012; Zhao et al., 2015).

Resulting from various methods and data sources, clear discrepancies exist in different emission inventories in China, at both national (Y. Zhao et al., 2013; Xia et al., 2016) and local scales (Zhao et al., 2015). When applied in CTM, the uncertainties in emission estimation would inevitably lead to biases in air quality simulation, besides the errors of meteorological field modeling and deficiencies of builtin atmospheric chemical mechanisms (Zheng et al., 2012). Based on the Models-3 Community Multi-scale Air Quality (CMAQ) system, for example, Zhang et al. (2014) simulated $\mathrm{PM}_{2.5}$ and $\mathrm{O}_{3}$ concentrations in the southeastern United States using the different versions of national emission inventory (NEI), and compared the results with several ground observational datasets. The model performance with updated inventory (NEI05) was much better than that with the old one (NEI99), indicating the impacts of emission inventory on the accuracy of CMAQ simulations. Han et al. (2015) conducted $\mathrm{NO}_{2}$ vertical column simulation for China with CMAQ, and found that the modeled results using INTEX-B inventory were closer to satellite observation than those using REAS. At regional or local scales, an emission inventory that incorporates the detailed information of individual sources is assumed to have advantages in air quality research prior to a downscaled national inventory that generally applied regional average levels of emission factors due to unavailability of data (Zhao et al., 2015). The benefits of improved emission estimation, spatial and temporal distribution, or chemical speciation of pollutants, however, have not been sufficiently confirmed with CTM. Recently, Yin et al. (2015) conducted the CMAQ simulation on $\mathrm{O}_{3}$ using an updated VOC emission inventory for PRD, implying that the reduced uncertainties of total emission estimation and spatial distribution could improve the model performance compared with ground observation.

We select Jiangsu, a typical province with well-developed industry in eastern China, to develop and evaluate the highresolution emission inventory. The geographic location and cities of the province are illustrated in Fig. S1 in the Supplement. With a total area of $107200 \mathrm{~km}^{2}$ and population of 79.2 million (in 2012), Jiangsu was the first ranked province in gross domestic product (GDP) per capita in China (NBSC, 2013a; JSNBS, 2013). It accounted for 8.0, 7.6, 8.9, and $10.2 \%$ of the country's power generation, cement, pig iron, and crude steel production in 2012, respectively (NBSC, 2013b). Intensive energy consumption and industry resulted in heavy air pollution: all 13 cities had their annual average concentrations of $\mathrm{PM}_{2.5}$ exceeding the NAAQS in 2012, with the highest reaching $74 \mu_{\mathrm{g} \mathrm{m}}^{-3}$ in the capital city, Nanjing. Clear uncertainties exist in current multi-scale emission in- 
ventories. Zhao et al. (2015), for example, estimated Nanjing's $\mathrm{SO}_{2}$ and $\mathrm{PM}_{2.5}$ emissions at 165 and $71 \mathrm{Gg}$ in 2012, respectively, while the results by Fu et al. (2013) were 131.8 and $35.3 \mathrm{Gg}$, implying the necessity of improvement and assessment of regional emission inventory, for both scientific and policy implication. In this work, a comprehensive emission inventory for Jiangsu, with high temporal and spatial resolutions, was first established with the best available data of local emission sources incorporated. This provincial emission inventory was then compared with other inventories and satellite observation to test its improvement on emission estimation and spatial distribution. CMAQ was further applied to indicate the advantage of the provincial inventory prior to downscaled national and regional ones. In particular, the impacts of spatial distribution of emissions on model performance were analyzed for periods with unfavorable meteorological conditions. Finally, the improved inventory was applied for sensitivity analysis on regional $\mathrm{PM}_{2.5}$ and $\mathrm{O}_{3}$ formation.

\section{Data and methods}

\subsection{Methodology of provincial emission inventory development}

The emissions of gaseous pollutants $\left(\mathrm{SO}_{2}, \mathrm{NO}_{x}, \mathrm{CO}, \mathrm{NH}_{3}\right.$ and VOCs), greenhouse gas $\mathrm{CO}_{2}$, particulate matter (total suspended particulates, TSP, $\mathrm{PM}_{10}$ and $\mathrm{PM}_{2.5}$ ) and its chemical compositions (black carbon, $\mathrm{BC}$ and organic carbon, OC) of anthropogenic origin in Jiangsu were estimated with a bottom-up method. Emission sources were classified into seven main categories, including power plant, industry, solvent use, transportation, residential and commercial, agriculture, and other sources. Industry was subdivided into iron and steel, cement, and other industry including nonferrous metal smelting, brick and lime kilns, chemical industry, and other industry boilers. Residential and commercial sector included household combustion of fossil fuel and biofuel. Agriculture included livestock and fertilizer usage. Open biomass burning, cooking, and waste (water) disposal, were considered as other sources. The detailed categories were summarized in Table S1 in the Supplement. Point, mobile, and area sources were defined for each category depending on the detailed levels of information and the emission characteristics. For point sources, information on emission factor and activity level was investigated and compiled for individual plants, and the annual emissions of atmospheric pollutants were calculated using Eq. (1), as described in Zhao et al. (2015).

$E_{i}=\sum_{j, m} \mathrm{AL}_{i, j, m} \times \mathrm{EF}_{i, j, m} \times\left(1-\eta_{i, j, m}\right)$,

where $i, j$, and $m$ represent the pollutant species, individual plant, and fuel or technology type, respectively, AL is the activity level data, EF is the uncontrolled emission factor, and $\eta$ is the removal efficiency of air pollutant control device.
Regarded as mobile sources, the emissions of on-road transportation were calculated by the CORPERT model (EEA, 2012) and then spatially allocated based on the road net information of the province. Area sources included nonroad transportation, solvent use, residential and commercial sector, agriculture, and small industry plants without detailed information collected. The emissions from non-road transportation and agriculture were estimated following the methods by Zhang et al. (2010) and Dong et al. (2009), respectively. For other sources, the emissions were calculated using Eq. (2)

$E_{i, n}=\sum_{m} \mathrm{AL}_{i, m, n} \times \mathrm{EF}_{i, m, n} \times\left(1-\eta_{i, m, n}\right)$,

where $n$ represents the source type and $\mathrm{EF}_{n}$ and $\eta_{n}$ are the average levels of uncontrolled emission factors and removal efficiencies for given source $n$, respectively. For sources without any emission control measure (e.g., residential combustion), $\eta=0$.

\subsection{Activity level}

The main sources of activity data are summarized by category in Table S1 in the Supplement. Most of coals in Jiangsu were used by power and industry sectors, and household accounted for only $0.3 \%$ of total coal consumption in the province in 2012 (JSNBS, 2013), indicating the significance of reducing the uncertainties of emission estimation for power and industry plants. Therefore a comprehensive database for power and industrial sector was established with the information collected and modified from the official environmental statistics, Pollution Source Census (PSC, internal data), and on-site surveys on large emitters. Parameters including geographical location, combustion or production technology, fuel/burner/boiler type, installed air pollution control device (APCD), and its removal efficiency were investigated for individual plants. In total 6750 plants were identified as point sources, including 191 power plants, 185 iron and steel plants, 231 cement factories, 707 lime and brick factories, 365 chemical plants and 5071 other industrial factories, as illustrated in Fig. S2 in the Supplement. In particular, the kilns for combustion and factories for calcination were separately investigated for cement production, and $25 \%$ of cement plants contained the both processes. For power, cement, and iron and steel sectors, the aggregated activity levels compiled plant by plant (i.e., the coal consumption of power generation and the production of cement, clinker, coke, pig iron, and crude steel) were estimated at 108, 95, $120,109,104$, and $98 \%$ of the provincial statistics, respectively (JSNBS, 2013). The comparison indicates, on the one hand, that larger activity levels would be obtained based on detailed investigation of individual emission sources rather than on official statistics for power and most processes of iron and steel sectors. On the other hand, an almost complete investigation on point sources was conducted for those sec- 
tors, as very small fractions of activities ( $5 \%$ for cement and $2 \%$ for steel production) had to be estimated as area sources. For other industrial sectors, smaller fractions of point sources were achieved, e.g., 32 and $36 \%$ for ammonia and sulfuric acid production, respectively.

For on-road transportation, the input parameters of COPERT 4 include regional meteorological information, vehicle population by type, fleet composition by control stage (China I-IV, equivalent to Euro I-IV), average vehicle speeds, and annual average kilometers traveled (VKT). Monthly mean temperature and relative humidity were obtained from the China Meteorological Data Sharing Service System (http:// www.escience.gov.cn). Populations of different vehicle types were derived from statistical yearbooks by city and then converted to the numbers in COPERT 4 categories. The fleet composition by control stage was obtained from the survey by local government (internal data, Zhao et al., 2015). Vehicle speed by road type (i.e., freeways and arterial and residential roads) and VKT by vehicle type were determined according to previous studies (Cai and Xie, 2007; Wang et al., 2008) and the guidebook of emission inventory development for Chinese cities (He, 2015). For area sources, the coal consumption of residential activities was directly taken from the National Energy Statistic Yearbook (NBSC, 2013c), while that of small industrial plants was calculated by subtracting the coal consumed by industrial point sources from the coal consumption of total industry provided in the provincial energy balance (NBSC, 2013c). The original data on the activity levels of agriculture, solvent use, non-road transportation and open biomass burning were obtained from the provincial or city statistical yearbooks (JSBNS, 2013).

\subsection{Emission factor}

Following previous studies (Zhao et al., 2008, 2010, 2011, 2012a, b; Y. Zhao et al., 2013), an emission factor database for Jiangsu was established, with detailed information and available results of emission measurements on local sources incorporated. For the power sector, parameters relevant to emission factors were obtained at individual plant level including installed capacity, fuel type and quality (e.g., sulfur and ash content), combustion technology, and the type and removal efficiencies of APCDs. In particular, the information of APCD installation obtained from provincial environmental statistics and on-site surveys was further corrected according to the official documents on APCD projects of power plants published by the Ministry of Environment Protection of China (http://www.zhb.gov.cn/gkml/hbb/bgg/201305/ t20130506_251654.htm). As summarized in Table S2 in the Supplement, the application rates of flue gas desulfurization (FGD), selective catalytic reduction (SCR) or selective noncatalytic reduction (SNCR), and dust collectors for Jiangsu's power plants in 2012 were 97,57 , and $99 \%$ in terms of coal consumption, and the average removal efficiencies of $\mathrm{SO}_{2}$, $\mathrm{NO}_{x}$, and TSP weighted by coal consumption were calcu- lated at 83.3, 37.1, and 98.0\%, respectively. Combining all the above-mentioned information, the emission factors for individual plant and facility were calculated using the methods developed by Zhao et al. (2010).

Table S3 in the Supplement summarizes the emission factors of the main industrial processes. For iron and steel production, emission factors of the four main manufacturing processes (coking, sintering, pig iron production, and steel making) were estimated by combining the unabated emission factors from previous database (Zhao et al., 2011; Y. Zhao et al., 2013) and the investigated information on penetrations and removal efficiencies of APCDs at plant level. Provided in Table S2, $64.3 \%$ of Jiangsu's iron and steel plants installed FGD in 2012 and the average $\mathrm{SO}_{2}$ removal efficiency was estimated at $78.0 \%$. Dust collectors were installed at almost all the furnaces for pig iron production and steel-making, with the averages of PM removal efficiency estimated at 96 and $94 \%$, respectively. For cement production, emission factors were calculated for the two main processes, coal combustion and calcination, following Lei et al. (2011). With dust collectors installed at $99 \%$ of plants, the average of overall removal efficiency on TSP was estimated at $97.3 \%$ according to our plant-by-plant investigation (Table S2).

For area sources, emission factors for non-road transportation were obtained from Zhang et al. (2010), Ye et al. (2014) and $\mathrm{Fu}$ et al. (2012). Emission factors for household fossil fuel and biofuel combustion were from the summary of field measurements in Y. Zhao et al. (2013). For agricultural activities including livestock and fertilizer use, emission factors were obtained from Dong et al. (2009) and Yin et al. (2010). Emission factors of VOCs were mainly from Wei et al. (2008) with an update for typical sources based on limited local measurements and surveys (Bo et al., 2008; EEA, 2013; Xia et al., 2014). The source profiles of VOC for Jiangsu were obtained following Li et al. (2014) with the most recent data from domestic results incorporated (Zhao et al., 2017).

\subsection{Temporal and spatial distributions}

The monthly variations of emissions from power plants and industrial sources were assumed to be dominated by the variations of electricity generation and typical industrial production, respectively, and those data were obtained from the $\mathrm{Na}-$ tional Bureau of Statistics of China (http://data.stats.gov.cn/). As the real-time monitoring on urban traffic was unavailable for the whole province, the temporal distribution of emissions from on-road vehicles in other cities was considered to the same as Nanjing (Zhao et al., 2015). For other sources, the temporal distributions for Shanghai, investigated by Li et al. (2011), were adopted.

Different parameters were used to conduct the spatial allocation of emissions by sector. Latitude and longitude of each point source collected from PSC were checked and revised according to Google Earth to avoid the un- 
expected errors in the existing database (Fig. S2 in the Supplement). The products of GDP (Huang et al., 2014) and population distribution with high resolution at $1 \mathrm{~km}$ (Fu et al., 2014) were applied to allocate the emissions from industrial area sources and residential and commercial sources, respectively. Emissions from on-road transportation were allocated based on the road net by city. As the ship flow was unavailable, the widths of Yangtze River and the Grand Canal within Jiangsu were used as indicators for ship emissions. Emissions from open biomass burning were allocated by the locations and brightness of agricultural fire spots observed by MODIS (Moderate Resolution Imaging Spectroradiometer, https://earthdata.nasa.gov/ data/near-real-time-data/firms). $\mathrm{NH}_{3}$ emissions from livestock and fertilizer usage were allocated based on the density of rural population and the distribution of agricultural lands obtained from the land utilization dataset GlobCover 2009 (http://due.esrin.esa.int/page_globcover.php).

\subsection{Configuration of air quality modeling}

The Models-3 Community Multi-scale Air Quality (CMAQ) version 4.7.1 was applied to evaluate the emission inventory for Jiangsu. As shown in Fig. 1, three one-way nested domain modeling was conducted, and the spatial resolutions were set at 27, 9, and $3 \mathrm{~km}$ respectively in Lambert Conformal Conic projection, centered at $\left(110^{\circ} \mathrm{E}, 34^{\circ} \mathrm{N}\right)$ with two true latitudes 25 and $40^{\circ} \mathrm{N}$. The mother domain (D1, $180 \times 130$ cells) covered most parts of China, Japan, North and South Korea, and parts of other countries. Jiangsu, Zhejiang, Shanghai, Anhui and parts of other provinces were at the second modeling region (D2, $118 \times 97$ cells). The third (D3, $124 \times 70$ cells) covered the megacity Shanghai and six most developed cities in southern Jiangsu including Nanjing, Changzhou, Zhenjiang, Wuxi, Suzhou, and Nantong. The simulation period was selected from 1 to 31 October 2012, with the first five days chosen as a spin-up period to provide initial conditions for later simulations.

Meteorological fields were provided by the Weather Research and Forecasting Model (WRF) version 3.4 with the main physical options set as Fu et al. (2013), and the outputs were transferred by meteorology chemistry interface professor (MCIP) version 4.2 into the chemistry transport module in CMAQ (CCTM). In WRF, the U.S. Geological Survey (USGS) database was adapted as terrain and land-use data, and the first guess field of meteorological modeling was provided by the final analysis dataset (ds083.2) from National Centers for Environmental Prediction (NCEP). Statistical indicators including bias, index of agreement (IOA), and root mean squared error (RMSE) were applied to evaluate the performance of WRF modeling against observation (Baker, 2004; Zhang et al., 2006). Ground observations at $3 \mathrm{~h}$ intervals at meteorological stations were downloaded from National Climatic Data Center (NCDC), including 43 stations in the second modeling domain D2 and 7 stations in the in- nermost domain D3 (as labeled in Fig. 1). The statistics of those indicators for wind speed and direction at $10 \mathrm{~m}$ (WS10 and WD10), temperature at $2 \mathrm{~m}$ (T2) and relative humidity at $2 \mathrm{~m}$ (RH2) for October 2012 in D2 and D3 were summarized in Table S4. Discrepancies between WRF simulations and ground observations were within acceptable range (Emory et al., 2001) and comparable to the results of other studies (Wang et al., 2014). Better agreements were found for simulations of T2 and RH2 than for WS10 and WD10. In spite of moderate overestimation by 0.3 and $3.5 \%$ in $\mathrm{T} 2$ and $\mathrm{RH} 2$, the IOA of those two variables were 0.97 and 0.90 , indicating high consistency with observations. Simulated WS10, which is slightly higher than observation in D2 and D3, might eventually enhance the diffusion process of pollutants in the atmosphere and thus lead to underestimation in pollutant concentrations. For WD10, the bias between simulations and observations was $3.6^{\circ}$ in D3 within the benchmark range (Emery et al., 2001).

The carbon bond gas-phase mechanism (CB05) and AERO5 aerosol module were adopted in all the CMAQ modules. The initial concentrations and boundary conditions for the first modeling domain was the default clean profile, while for the nested domain they were extracted from the CCTM outputs of its mother domain. Anthropogenic emissions used for domains D1 and D2 were obtained from the downscaled MEIC with an original spatial resolution of $0.25^{\circ} \times 0.25^{\circ}$. For Jiangsu domain in D3, three inventories (i.e., downscaled MEIC), the regional inventory of YRD by Fu et al. (2013), and the provincial inventory developed in this work were used to test the modeling performance and potential improvement in emission estimation. In addition, the biogenic emission inventory was from the Model Emissions of Gases and Aerosols from Nature developed under the Monitoring Atmospheric Composition and Climate project (MEGANMACC, Sindelarova et al., 2014), and the emission inventories of $\mathrm{Cl}, \mathrm{HCl}$ and lightning $\mathrm{NO}_{x}$ were from the Global Emissions Initiative (GEIA, Price et al., 1997). The vertical distributions of emissions were taken directly from L. Wang et al. (2010) except for the power sector, as the height of discharge outlet for each plant was available. According to L. Wang et al. (2010), the fractions of emissions of industry sources were 50,30 , and $20 \%$ in layers $1-3$, respectively. For the sources near the surface (i.e., transportation, residential and commercial combustion, solvent use, agriculture, and other sources), emissions were overall allocated to the first vertical layer in the model. The emissions of power plants were concentrated in layers $2-5$ with the fractions estimated at $14,46,35$, and $5 \%$, respectively, based on the height information of the stacks. 


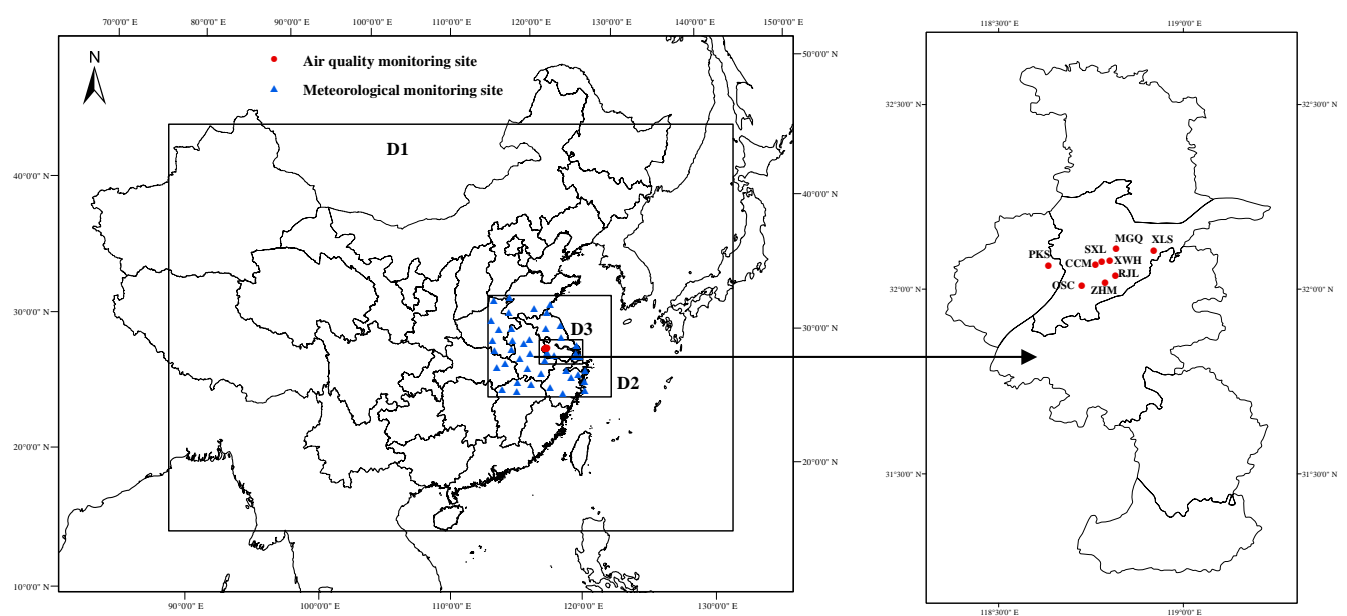

Figure 1. Modeling domain and locations of 43 meteorological and 9 air quality monitoring sites.

Table 1. The estimated annual emissions by city for Jiangsu 2012 (unit: million metric tons ( $\mathrm{Tg}$ ) for $\mathrm{CO}_{2}$ and kilo metric tons (Gg) for other species).

\begin{tabular}{lrrrrrrrrrrr}
\hline City & $\mathrm{SO}_{2}$ & $\mathrm{NO}_{x}$ & $\mathrm{CO}$ & $\mathrm{TSP}$ & $\mathrm{PM}_{10}$ & $\mathrm{PM}_{2.5}$ & $\mathrm{BC}$ & $\mathrm{OC}$ & $\mathrm{CO}_{2}$ & $\mathrm{NH}_{3}$ & $\mathrm{VOCs}^{2}$ \\
\hline Southern & & & & & & & & & & \\
\hline Nanjing & 140.6 & 210.5 & 742.9 & 157.3 & 97.3 & 75.8 & 5.8 & 7.1 & 97.1 & 64.2 & 221.9 \\
Suzhou & 220.8 & 286.7 & 1383.3 & 380.6 & 194.9 & 137.3 & 9.8 & 11.0 & 184.4 & 144.8 & 297.8 \\
Wuxi & 107.7 & 180.0 & 545.5 & 271.3 & 126.9 & 77.2 & 3.4 & 9.6 & 84.5 & 24.2 & 167.2 \\
Changzhou & 104.0 & 107.7 & 734.6 & 413.3 & 194.6 & 126.2 & 3.6 & 7.5 & 65.2 & 33.4 & 104.2 \\
Zhenjiang & 44.0 & 89.6 & 231.6 & 143.3 & 66.8 & 40.9 & 1.9 & 6.6 & 53.0 & 38.1 & 55.4 \\
\hline Central & & & & & & & & & & & \\
\hline Nantong & 76.8 & 130.1 & 443.4 & 244.9 & 108.2 & 66.0 & 4.8 & 9.3 & 51.6 & 181.7 & 162.2 \\
Yangzhou & 55.3 & 93.9 & 310.7 & 54.1 & 39.9 & 31.1 & 2.6 & 8.5 & 52.1 & 83.1 & 82.5 \\
Taizhou & 56.6 & 70.5 & 315.1 & 207.6 & 98.2 & 52.3 & 2.7 & 8.8 & 31.4 & 100.7 & 76.9 \\
\hline Northern & & & & & & & & & & & \\
\hline Xuzhou & 138.9 & 232.5 & 805.5 & 223.2 & 146.5 & 101.9 & 6.1 & 19.1 & 139.2 & 49.2 & 161.2 \\
Huai'an & 52.2 & 61.5 & 590.0 & 97.4 & 64.5 & 49.5 & 3.7 & 12.0 & 32.5 & 195.9 & 78.6 \\
Yancheng & 49.9 & 78.5 & 639.7 & 203.8 & 111.8 & 72.0 & 5.6 & 16.1 & 28.2 & 101.0 & 185.0 \\
Lianyungang & 60.6 & 61.0 & 571.1 & 131.0 & 89.0 & 68.6 & 3.9 & 11.9 & 28.3 & 25.1 & 78.0 \\
Suqian & 34.1 & 39.7 & 366.8 & 77.8 & 55.5 & 42.3 & 3.2 & 11.0 & 12.9 & 59.1 & 76.4 \\
\hline Total & 1141.5 & 1642.2 & 7680.0 & 2605.6 & 1394.0 & 941.1 & 57.0 & 138.5 & 860.5 & 1100.3 & 1747.3 \\
\hline
\end{tabular}

\section{Results}

\subsection{Emission estimation and sector contribution}

The total annual emissions of $\mathrm{SO}_{2}, \mathrm{NO}_{x}, \mathrm{CO}$, TSP, $\mathrm{PM}_{10}$, $\mathrm{PM}_{2.5}, \mathrm{BC}, \mathrm{OC}, \mathrm{CO}_{2}, \mathrm{NH}_{3}$, and VOCs were calculated at 1142, 1642, 7680, 2606, 1394, 941, 57, 138, 860 458, 1100 and $1747 \mathrm{Gg}$ for Jiangsu in 2012, respectively. The emissions by city were provided in Table 1 . In general, higher emissions were found in cities in southern Jiangsu with large populations and intensive economy and industry than those in northern Jiangsu. Taking $52 \%$ of the provincial industrial
GDP, Suzhou, Nanjing, and Wuxi were estimated to collectively account for $41,41,35,31,43$ and $39 \%$ of the total emissions of $\mathrm{SO}_{2}, \mathrm{NO}_{x}, \mathrm{CO}, \mathrm{PM}_{2.5}, \mathrm{CO}_{2}$, and VOCs, respectively. Xuzhou, differently from other cities in northern Jiangsu, had a relative high emissions of pollutants due to its good development of large-scale industry. Because of the active agricultural development, $\mathrm{NH}_{3}$ emissions in Huai' an and Nantong were estimated at 195.9 and $187.1 \mathrm{Gg}$ respectively, significantly higher than other cities.

Shown in Fig. 2 is the detailed sector contribution of pollutants from point, mobile (on-road transportation) and area sources. The point sources including power and industrial 


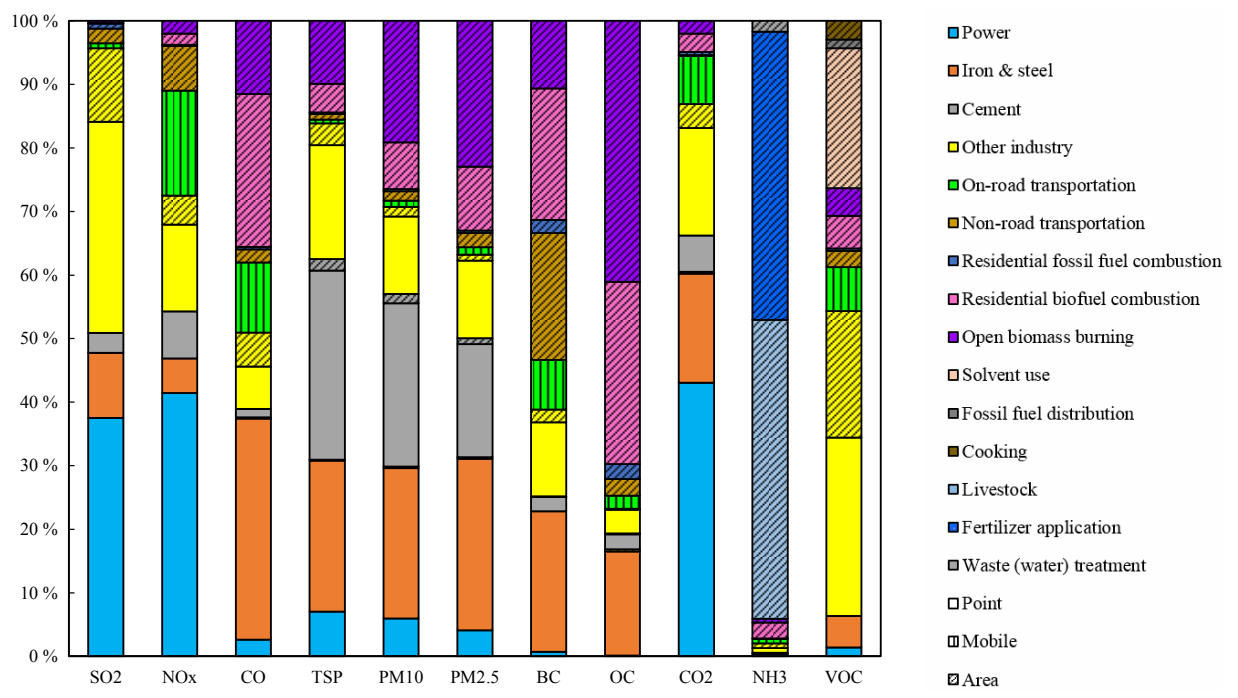

Figure 2. Source contributions to total estimated emissions by species in Jiangsu 2012. Colors indicate the sectors and the shade patterns indicate the source type (point, mobile, and area).

plants contributed $84,71,55,83,75,64,41,31,83,2$, and $36 \%$, to the total emissions of $\mathrm{SO}_{2}, \mathrm{NO}_{x}, \mathrm{CO}, \mathrm{TSP}, \mathrm{PM}_{10}$, $\mathrm{PM}_{2.5}, \mathrm{BC}, \mathrm{OC}, \mathrm{CO}_{2}, \mathrm{NH}_{3}$, and VOCs, respectively. Notably the emission fractions of point sources were larger than those in other regional inventories (Fu, 2009; Tang et al., 2012; B. Zhao et al., 2012), resulting mainly from the compiling and application of information on individual power and industrial plants from varied data sources. Defined as area source, open biomass burning contributed $12,19,23,11$, and $41 \%$ to the total $\mathrm{CO}, \mathrm{PM}_{10}, \mathrm{PM}_{2.5}, \mathrm{BC}$, and $\mathrm{OC}$, respectively.

The dominant contributors to $\mathrm{SO}_{2}$ were power plants, iron and steel production and other industrial sources, with the emission fractions estimated at 38,10 , and $45 \%$, respectively. Although the coal consumption in the power sector was 3.5 times larger than that in other industry sectors (cement and iron and steel production excluded, JSNBS, 2013), smaller contributions to $\mathrm{SO}_{2}$ emissions were found for coalfired power plants, implying the benefits of strict control on $\mathrm{SO}_{2}$ emissions from the power sector. As shown in Table S2, the application rate and average $\mathrm{SO}_{2}$ removal efficiency of FGD in the power sector were significantly higher than those in other industries, suggesting that the improvement in $\mathrm{SO}_{2}$ abatement for industrial coal combustion other than power plants would be an effective measure to further reduce the emissions at present.

The power sector was the largest source for $\mathrm{NO}_{x}$, contributing $41 \%$ to the total emissions, while the share of coal consumption of the sector reached $65 \%$ (JSNBS, 2013). It thus demonstrated the tightened controls from implementation of new emission standard (GB13223-2011) and improved use of SCR-SNCR on power plants since 2011 compared to other sectors. Compiled from unit level, the average $\mathrm{NO}_{x}$ removal efficiency of SCR-SNCR was calculated at $37 \%$ for Jiangsu's power plants in 2012 (Table S2), while Tian et al. (2013) estimated the values for SCR and SNCR at 70 and $25 \%$, respectively, indicating the differences in assessment of emission controls for the power sector between the provincial and national emission inventories with varied data sources. Transportation (including on-road and nonroad) was estimated to be the second largest sector for $\mathrm{NO}_{x}$ emissions, with its share of the total emissions calculated at $24 \%$. Without specific control measures, cement and other industrial sources were estimated to account for 7 and $18 \%$ of total $\mathrm{NO}_{x}$ emissions respectively.

$\mathrm{CO}$ was mainly generated from the manufacturing processes in iron and steel plants. The production of pig iron and crude steel in Jiangsu accounted for 9 and $10 \%$ to the national total in 2012, respectively (NBS, 2013), and was higher than other provinces in China except Hebei. Due to the intensive iron and steel industry, the contribution of the sector to the provincial total $\mathrm{CO}$ emissions was estimated at $35 \%$. Residential biofuel combustion, open biomass burning, and on-road transportation were also large contributors to $\mathrm{CO}$ with the emission fractions calculated as 24,12 , and $11 \%$ respectively.

For particles, iron and steel and cement production were estimated to be the largest sources, contributing 24 and $27 \%$ to the total emissions of $\mathrm{PM}_{10}$, and 27 and $19 \%$ to $\mathrm{PM}_{2.5}$, respectively. Even with the largest coal consumption among all the sectors, the emissions from power plants were relatively small (6 and $4 \%$ to the total $\mathrm{PM}_{10}$ and $\mathrm{PM}_{2.5}$ emissions, respectively), resulting mainly from the relatively high penetrations and removal efficiencies of dust collectors. Great differences existed in the sector distribution of $\mathrm{BC}$ and $\mathrm{OC}$ emissions. Iron and steel production was estimated to be the largest source of $\mathrm{BC}$, while open biomass burning and bio- 
fuel burning in residential stoves dominated OC, with the shares estimated at 41 and $29 \%$, respectively. Moreover, as $\mathrm{BC}$ exhausted from the diesel engines was demonstrated to be higher than $\mathrm{OC}$ in previous situ measurements (He et al., 2015), BC emissions from non-road transportation (agricultural machines, rural vehicles, ships and construction machines) were estimated to be more than twice as large as OC.

For VOCs, solvent use and other industry (including oil refinery, chemical industry, and combustion) were identified as the largest sources, contributing 30 and $29 \%$ to total emissions, respectively. In particular, oil refinery and chemical engineering collectively accounted for $74 \%$ of the emissions of other industry. Due to lack of investigation on chemical industry plants, the fraction of area sources to the emissions of other industries reached $35 \%$. Transportation and residential cooking are estimated to contribute 12 and $4 \%$ to total VOC emissions, respectively. Livestock and fertilizer use were the two dominating sources of $\mathrm{NH}_{3}$, with the shares to total emissions estimated at $47 \%$ and $45 \%$, respectively. For industry, ammonia production was the main source, accounting for half of $\mathrm{NH}_{3}$ emissions.

The spatial distributions of $\mathrm{SO}_{2}, \mathrm{NO}_{x}, \mathrm{CO}, \mathrm{PM}_{2.5}$, VOCs, and $\mathrm{NH}_{3}$ emissions were at a resolution of $3 \times 3 \mathrm{~km}$ and are illustrated in Fig. S3 in the Supplement (Zhou and Zhao, 2016). Outstandingly high emissions of $\mathrm{SO}_{2}, \mathrm{NO}_{x}, \mathrm{PM}_{2.5}$, and VOC indicated the existence of large industrial plants, particularly in Suzhou, Nanjing, and Wuxi along the Yangtze River. For $\mathrm{CO}$ and $\mathrm{NO}_{x}$, large emissions were distributed along the road net in the province, reflecting the important contribution of on-road transportation. Unlike other pollutants, high $\mathrm{NH}_{3}$ emissions were more evenly distributed in rural areas dominated by agricultural activities.

\subsection{Comparisons with other studies}

Figure 3 compares the emission estimations for Jiangsu between our provincial inventory and previous studies including two regional inventories (Fu et al., 2013; Li et al., 2011) and two national ones (MEIC; Xia et al., 2016). Note that this work and Xia et al. (2016) reported the numbers for 2012, while Fu et al. (2013), Li et al. (2011) and MEIC reported for 2010. As the emissions from open biomass burning were not included in other inventories, except for Fu et al. (2013) and this work, two values labeled as A and B were provided for our provincial inventory indicating the emissions with and without biomass open burning, respectively. While provincial economy and energy data were generally applied in all the national and regional inventories, information on individual large emitters were also incorporated in MEIC, Fu et al. (2013), and Li et al. (2011). For example, the emissions of big plants for power generation, iron and steel production, and cement production in Jiangsu were partially investigated in Fu et al. (2013) and Li et al. (2011). For MEIC, a large fraction of emissions from the power generation sector was calculated plant by plant with relatively good data availabil- ity, while emissions from other industrial sectors were basically calculated at regional average and spatially allocated as area sources. The results in Fu et al. (2013) were generally smaller than those in the other two inventories for 2010.

Attributed mainly to the improved use of FGD, the total $\mathrm{SO}_{2}$ emissions were estimated to decline from 2010 to 2012 for the whole country (Xia et al., 2016) and a typical city in Jiangsu (Zhao et al., 2015). It was reasonable to some extent that the $\mathrm{SO}_{2}$ emissions in Jiangsu estimated in this work for 2012 was less than the 2010 results of Li et al. (2011) and MEIC. Our estimation was $15 \%$ lower than the result for Jiangsu extracted from the national inventory by Xia et al. (2016), due mainly to the discrepancies in the penetration and $\mathrm{SO}_{2}$ removal efficiency of FGD applied in the two inventories. Such information was obtained at provincial or national average level by Xia et al. (2016), in contrast to the provincial inventory based on investigation at plant level. For example, Xia et al. (2016) assumed that the penetration rates of wet and dry FGD technologies in the coal-fired power sector were 83 and $5 \%$ in 2012, with the removal efficiencies estimated at 80 and $40 \%$, respectively, and that there was not any $\mathrm{SO}_{2}$ control in the remaining $11 \%$ of installed capacity at all. According to our plant-based investigation, the controls in Jiangsu were clearly enhanced, as shown in Table $\mathrm{S} 2$. As a result, $\mathrm{SO}_{2}$ emissions from the power sector was calculated at $430.0 \mathrm{Gg}$ for Jiangsu 2012 in this work, $42 \%$ lower than those in Xia et al. (2016). The result for 2012 in our provincial inventory, however, is very close to the estimation by MEIC for 2010 (437.4 Gg), even though the coal consumption of power generation increased $29 \%$ for the period 2010-2012 (JSNBS, 2013). Besides the uncertainty in emission estimation from varied data sources of the two inventories, the improved use of FGD in the sector could be an important reason for the restrained emissions. Similar data found for Nanjing, the capital city of Jiangsu, showed that the $\mathrm{SO}_{2}$ emissions of power generation calculated at city level was kept stable along with a $25 \%$ growth of coal consumption from 2010 to 2012 (Zhao et al., 2015).

$\mathrm{NO}_{x}$ emissions in our provincial inventory was slightly higher than those of Li et al. (2011) and clearly lower than the two national inventories. The major difference between the provincial inventory and MEIC was from industry, probably attributable to the application of varied emission factors. With different methods and data sources for certain sectors, the $\mathrm{NO}_{x}$ emissions from industry were calculated at 388.1 and $566.2 \mathrm{Gg}$ respectively by this work and Xia et al. (2016). For on-road transportation, the emission factors were estimated using CORPERT in this work, while they were obtained from limited domestic measurements in Xia et al. (2016). That was also the most important reason for the discrepancies in $\mathrm{CO}$ emission estimation between the two studies. For 2010, the $\mathrm{NO}_{x}$ emissions estimated by $\mathrm{Fu}$ et al. (2013) were 18 and $36 \%$ lower than those by $\mathrm{Li}$ et al. (2011) and MEIC, resulting mainly from the higher ap- 


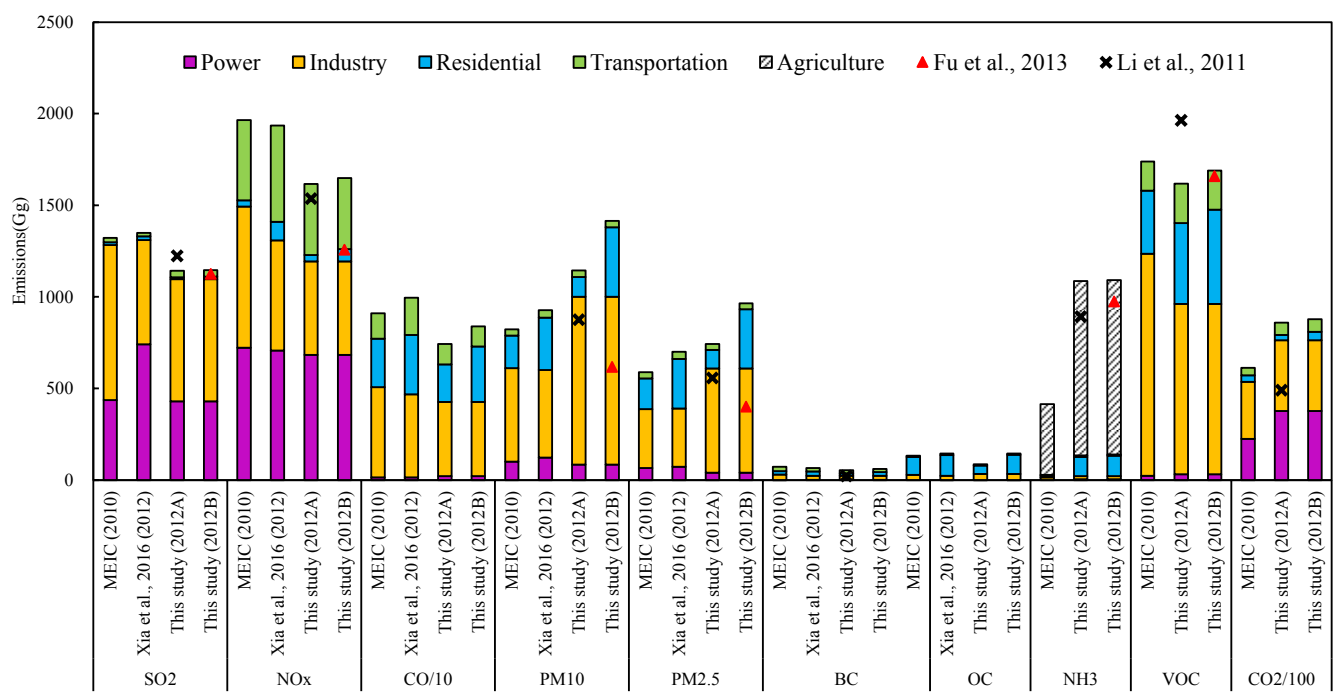

Figure 3. Comparison between the emissions estimated in this work and other studies for Jiangsu. A and B indicate the emissions without and with open biomass burning, respectively.

plication rate and removal efficiency of SCR or SNCR technologies for the power sector used in Fu et al. (2013).

The $\mathrm{PM}_{2.5}$ and $\mathrm{PM}_{10}$ emissions in the provincial inventory were estimated to be 6 and $23 \%$ higher, respectively, than those of Xia et al. (2016), and the sector contributions were notably different in the two inventories. For example, industry was estimated to contribute 77 and $80 \%$ of $\mathrm{PM}_{2.5}$ and $\mathrm{PM}_{10}$ in the provincial inventory, much larger than the fractions at 45 and $52 \%$ by Xia et al. (2016), respectively. In this work, the $\mathrm{PM}_{2.5}$ and $\mathrm{PM}_{10}$ emissions from cement production were calculated at 181 and $384 \mathrm{Gg}$, i.e., 2.5 and 2.0 times those in Xia et al. (2016), and the analogue numbers for iron and steel production were 134 and $263 \mathrm{Gg}$, and 1.8 and 1.7 times those in Xia et al. (2016), respectively. The discrepancies resulted mainly from the inconsistent penetration rates and removal efficiencies of dust collectors determined at national level and from on-site surveys at provincial level. Taking cement as an example, all the plants were assumed to be installed with dust collectors, and the national average removal efficiency at $99.3 \%$ was applied in Xia et al. (2016), clearly larger than that from plant-by-plant surveys as shown in Table S2. Note that the particle emissions in the provincial inventory were estimated to be higher than those in national ones including MEIC and Xia et al. (2016), while the gaseous pollutant emissions were lower except for $\mathrm{NH}_{3}$ and $\mathrm{CO}_{2}$. Compared to the emissions for 2010 estimated by other studies, the $\mathrm{PM}_{2.5}$ and $\mathrm{PM}_{10}$ in our provincial inventory were 58 and $56 \%$ larger than Fu et al. (2013) (biomass open burning included), and 24 and $25 \%$ larger than $\mathrm{Li}$ et al. (2011) (biomass open burning excluded), respectively, beyond the growth rate of $20 \%$ for coal consumption during 2010-2012 (NBS, 2011, 2013).
The $\mathrm{NH}_{3}$ emissions of Fu et al. (2013) and Li et al. (2011) were close to each other, while MEIC was only half of those for 2010. Using the results for 2006 from Huang et al. (2012), MEIC made a very low estimation in $\mathrm{NH}_{3}$ emissions from livestock. The $\mathrm{NH}_{3}$ emissions for 2012 in this work were calculated to be 11 and $22 \%$ larger than the results for 2010 by Fu et al. (2013) and Li et al. (2011), respectively. According to the provincial statistics, the total numbers of livestock and poultry increased 6 and $10 \%$, respectively, from 2010 to 2012 in Jiangsu (JSNBS, 2013). The growth of activity levels was expected to result in enhanced emissions, as very little progress was achieved in $\mathrm{NH}_{3}$ control for these years.

\subsection{Analysis of spatial distribution of emissions from given sectors}

To further explore the discrepancies in emission estimation and spatial distribution from varied data and emission allocation methods, comparisons between MEIC and our provincial inventory were conducted for pollutants from typical sources, including $\mathrm{SO}_{2}$ from power plants, $\mathrm{NO}_{x}$ from transportation, and $\mathrm{PM}_{2.5}$ from industry. The estimates in this work were reallocated into the $0.25^{\circ} \times 0.25^{\circ}$ grids, consistent with the spatial resolution of MEIC, and the correlation coefficients for emissions in all the grids can be calculated, as shown in Fig. 4. Due mainly to the relatively transparent and easily available information of power plants, good consistency was found for $\mathrm{SO}_{2}$ emissions from the power sector in the two inventories, with the correlation coefficient calculated at 0.7 (Fig. 4a). Even though the fundamental information of power plants in China is more accessible than other industry sources, mismatches still exist in different data sources. For example, some emission hotspots in our provincial inventory were not totally identical with those in MEIC 
(a)

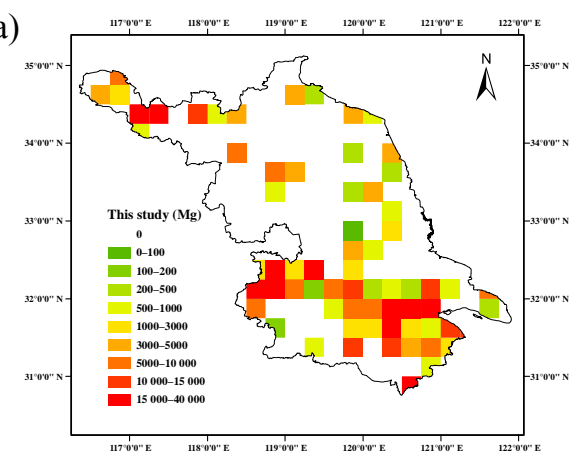

(b)

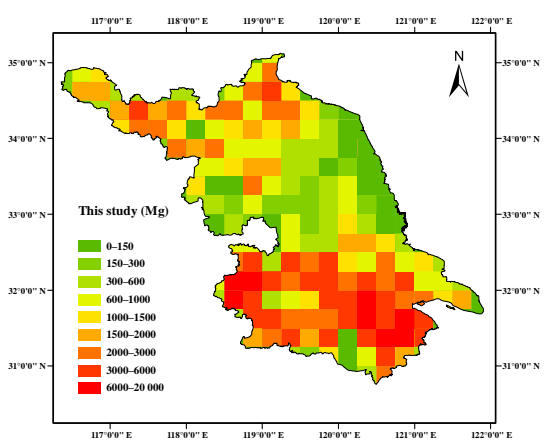

(c)

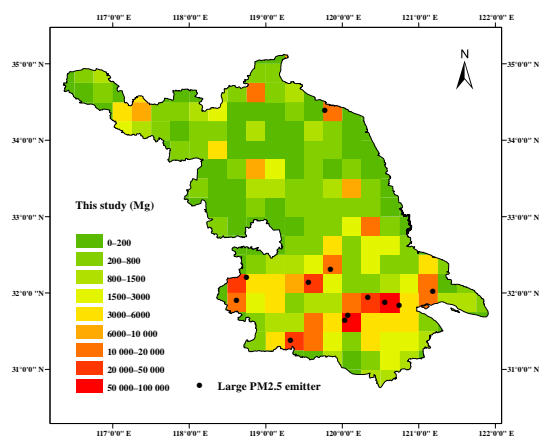

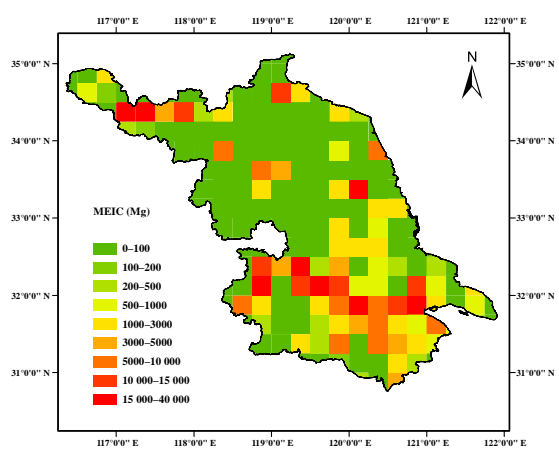
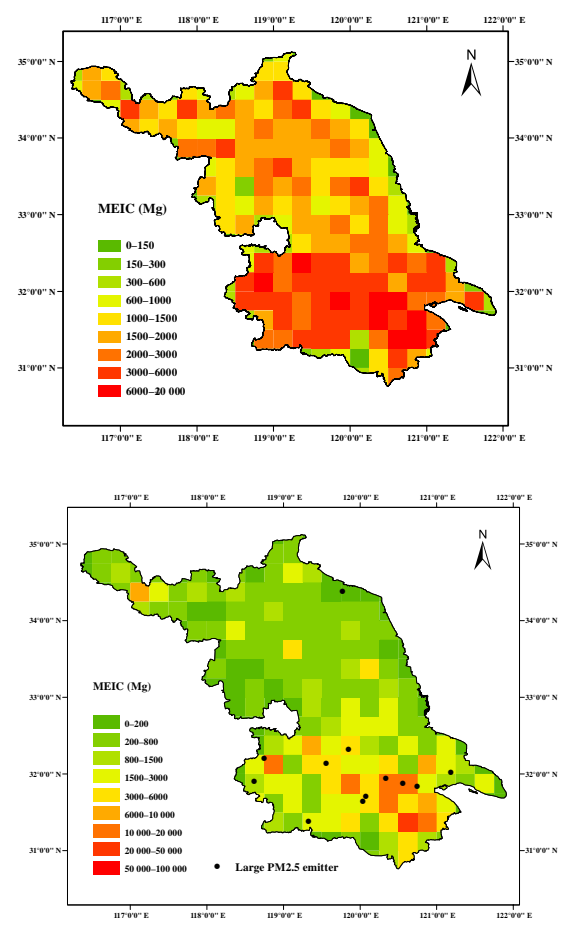

(d)

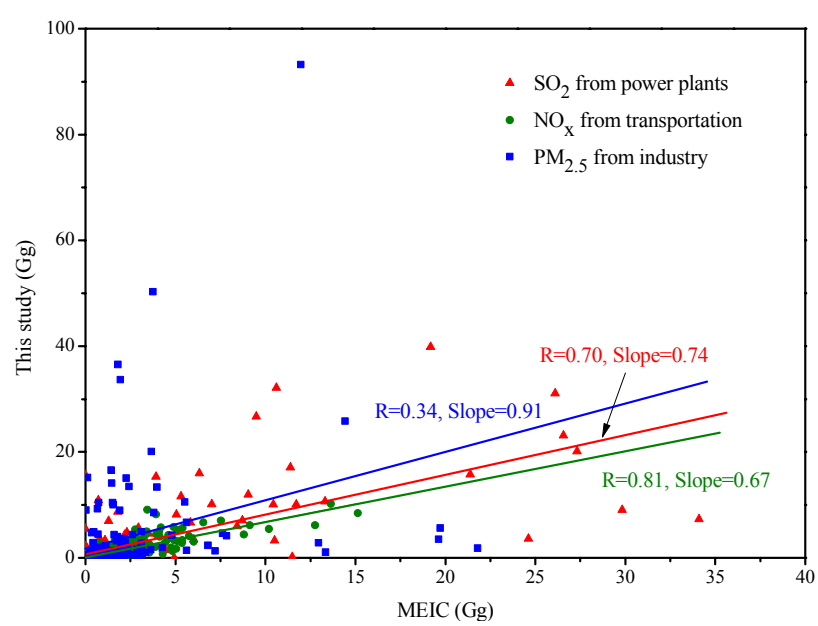

Figure 4. Spatial distributions (a-c) and linear regression (d) of certain pollutant emissions from typical sources estimated in our provincial inventory and MEIC. (a) $\mathrm{SO}_{2}$ from power plants; (b) $\mathrm{NO}_{x}$ from transportation; (c) $\mathrm{PM}_{2.5}$ from industry. The black points indicate the locations of plants with $\mathrm{PM}_{2.5}$ emissions larger than $10 \mathrm{Gg}$ estimated in this work. 
in Suzhou, Nantong, and Nanjing. In contrast to plant-byplant investigation, the data from existing statistics at national level could not fully track the actual changes in the emitters, e.g., operation of new-built units, shutting down the small ones, or relocation of individual plants. In MEIC, moreover, the $\mathrm{SO}_{2}$ emissions in several grids were estimated to be extremely small (less than $1 \mathrm{Mg}$ ), indicating that part of the emissions from the power sector were still allocated as area sources based on density of GDP or population. In contrast, all the plants were identified as point sources in the provincial inventory, based on the thorough investigation on individual sources.

For $\mathrm{NO}_{x}$ from transportation, the correlation coefficient was calculated at 0.8 , indicating an even better consistency than $\mathrm{SO}_{2}$ from power plants between the two inventories (Fig. 4b). Although the difference in total emissions was small between our provincial inventory $(682 \mathrm{Gg})$ and MEIC $(722 \mathrm{Gg})$, the estimation of MEIC was notably higher than our result for northern Jiangsu including Yancheng, Huai' an, and Suqian, implying the impacts from different ways for emission allocation. In this work, emissions from on-road vehicles were calculated and allocated based on road net that incorporates the information of transportation flow by road grade for each city. For non-road sources, large fraction of emissions was allocated based on the GDP density associated with land-use type. In national emission inventories, however, the emissions were first calculated at provincial level, and then downscaled at certain horizontal resolution. Despite the discrepancies, it could be indicated by the relatively high spatial correlation between the two inventories that using GDP as proxy for emission allocation would be acceptable when detailed information on road net and transportation flow was unavailable, since vehicles were largely concentrated in the downtown area because of the intensive economic activity.

For $\mathrm{PM}_{2.5}$ from industry, the correlation coefficient was calculated at 0.335 , significantly lower than those mentioned above, indicating larger discrepancies in spatial distribution of industrial emissions between provincial and national inventories compared to power and transportation sectors. As shown in Fig. 4c, the emission hotspots in the provincial inventory are highly consistent with the locations of large industrial $\mathrm{PM}_{2.5}$ emitters (more than $10 \mathrm{Gg}$ ) estimated in this work, while the emissions in MEIC were more distributed in developed cities (e.g., Suzhou) with high density of population or economy. Along with fast urbanization, super industrial sources have gradually been relocated to the rural and suburban areas, and the spatial correlation between industrial emissions and population could thus be weakened. In our provincial inventory, most industrial enterprises were identified as point sources, with the key parameters including geographic location, activity level, and removal efficiency of dust collectors investigated and corrected at plant level. In MEIC, the emissions were calculated using parameters at regional average level and allocated as area sources according to densities of population and/or economic activity. Without detailed information for individual sources, it might lead to errors in emission estimation and spatial distribution at regional or local scale. According to the survey at plant level, for example, only $20 \%$ of the lime factories had installed dust collectors in Jiangsu 2012, much lower than the value (roughly $90 \%$ ) assumed in national inventories. As a result, the $\mathrm{PM}_{2.5}$ emissions from industry were calculated at $570 \mathrm{Gg}$ in our provincial inventory, $78 \%$ higher than those of MEIC.

\section{Assessment of the provincial emission inventory}

\subsection{Evaluation of spatial distribution of $\mathrm{NO}_{x}$ emissions with satellite observation}

Tropospheric $\mathrm{NO}_{2}$ vertical column density (VCD) retrieved from an ozone monitoring instrument (OMI) by the Royal Netherlands Meteorological Institute (Boersma et al., 2011) was employed to test the spatial distribution of $\mathrm{NO}_{x}$ emissions in MEIC and this work. Tropospheric $\mathrm{NO}_{2}$ over China obtained using this product is consistent with $\mathrm{NO}_{2}$ data from ground-based measurements with multi-axis DOAS $\left(R^{2}=\right.$ 0.96; Lin et al., 2014). Since clouds reduce the accuracy of satellite measurements, only pixels with cloud fraction $\leq 0.2$ have been analyzed. $\mathrm{NO}_{2} \mathrm{VCDs}$ in summer were used due to the short lifetime of $\mathrm{NO}_{2}$ in the atmosphere at high temperatures and the difficulty in accumulation for primary emissions with strong air convection. In addition, the summer prevailing wind for Jiangsu was generally from the southeast where Shanghai and Zhejiang Province are located (see Fig. S1 for the locations of the three regions). Total $\mathrm{NO}_{x}$ emissions of Jiangsu were estimated to be 65 and $282 \%$ larger, respectively, than those of Zhejiang and Shanghai in MEIC, indicating that the local sources played an important role in the air pollution formation for the province (Cheng et al., 2011). As Mijling et al. (2013) illustrated that satellite observations could be used to evaluate the primary emissions for regions where $\mathrm{NO}_{2} \mathrm{VCDs}$ were mainly affected by local emissions, it was thus feasible to apply the $\mathrm{OMI} \mathrm{NO}_{2} \mathrm{VCDs}$ in Jiangsu to assess its $\mathrm{NO}_{x}$ emissions.

$\mathrm{NO}_{2}$ VCDs in July 2010 and 2012, with original spatial resolution of $0.125^{\circ} \times 0.125^{\circ}$, were used for comparisons with the emissions in MEIC and our provincial inventory, respectively. To be consistent with MEIC, the emissions in our provincial inventory and the $\mathrm{NO}_{2} \mathrm{VCD}$ from OMI were first upscaled to $0.25^{\circ} \times 0.25^{\circ}$ for the purpose of visualization and correlation analysis. As can be seen in Fig. 5a and b, clear reduction in summer $\mathrm{NO}_{2}$ VCDs was found in southern Jiangsu from 2010 to 2012, indicating the benefits of efforts on $\mathrm{NO}_{x}$ abatement since 2011. The $\mathrm{NO}_{2} \mathrm{VCDs}$ in the area along the Yangtze River were notably higher than those in other regions, attributable possibly to the substantial emissions from vessels and small captive power plants of the chemical and refinery industrial parks along the river, 
$\mathrm{NO}_{2} \mathrm{VCDs}$

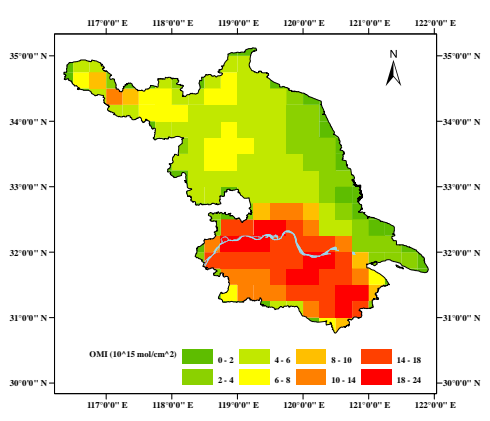

(a)

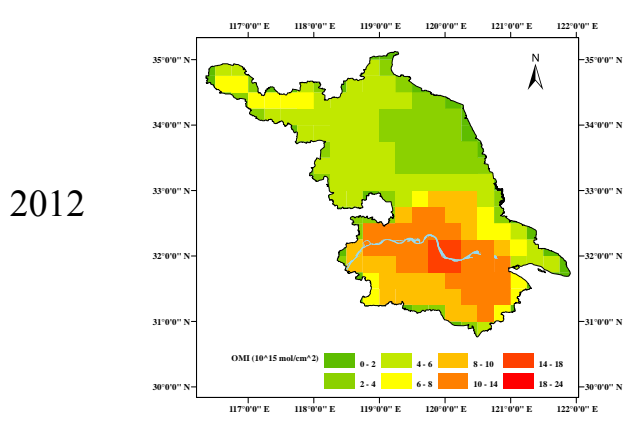

(b)
NOx emission

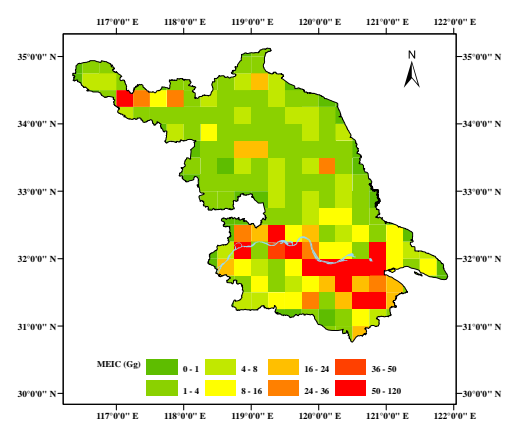

(c)

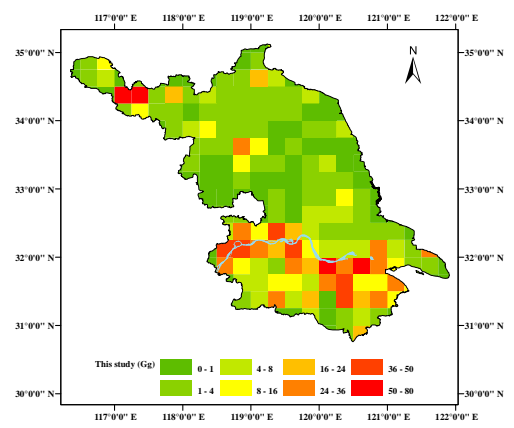

(d)
Linear regression

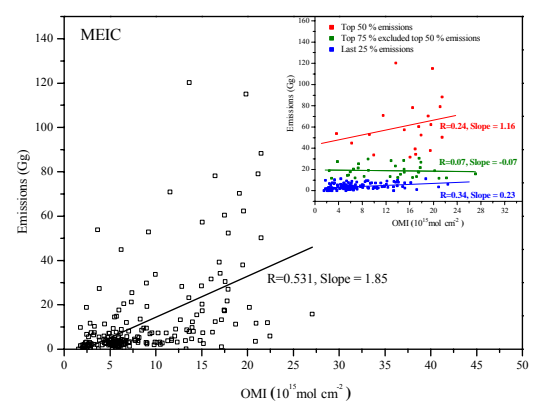

(e)

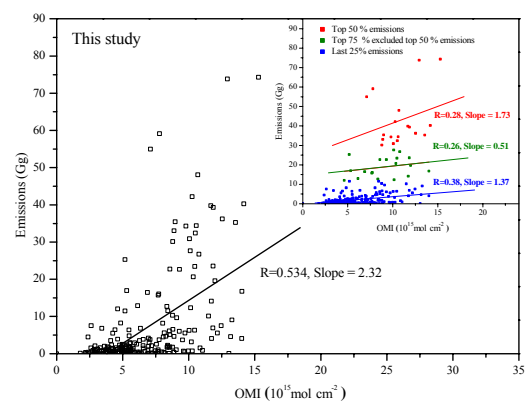

(f)

Figure 5. Spatial distributions of $\mathrm{NO}_{2}$ VCDs observed by OMI in Jiangsu in 2010 (a) and 2012 (b), and those of Jiangsu's NO emissions $^{2}$ from MEIC (c) and our provincial inventory (d) at the resolution of $0.25^{\circ} \times 0.25^{\circ}$. Linear regressions of gridded VCDs and emissions are illustrated for MEIC (e) and our provincial inventory (f).

which do not have controls as stringent as those for big power plants. Shown in Fig. $5 \mathrm{c}$ and $\mathrm{d}$ are the spatial distributions of Jiangsu's $\mathrm{NO}_{x}$ emissions in MEIC and our provincial inventory, respectively, and the emission hotspots were generally consistent between the two inventories. Figure 5e and $\mathrm{f}$ shows the linear regression results between $\mathrm{NO}_{2}$ VCDs and $\mathrm{NO}_{x}$ emissions in MEIC and the provincial inventory, respectively. The correlation coefficients between VCDs and emissions were separately provided for all the grids and grids in different emission intervals, i.e., top 50, 50-75, and last $25 \%$.

The correlation coefficient between $\mathrm{NO}_{2}$ VCDs and $\mathrm{NO}_{x}$ emissions from the provincial inventory was 0.534 , close to that between $\mathrm{NO}_{2}$ VCDs and MEIC at 0.531. The result indicated that there was no significant difference in spatial distribution of emissions between the national and provincial inventories at the relatively low horizontal resolution. However, great discrepancies existed when the correlation analysis was conducted for grids in different emission intervals. As shown in Fig. 5e, the correlation coefficients between VCDs and MEIC emissions were calculated at 0.24 and 0.34 , respectively, for the top $50 \%$ (20 grids with emissions ranged $32-121 \mathrm{Gg}$ ) and last $25 \%$ of gridded emissions (161 grids with emissions ranged $0-12 \mathrm{Gg}$ ). For our provincial emission inventory, the correlation coefficients were estimated to be slightly higher, at 0.28 and 0.38 respectively, for the top $50 \%$ (18 grids with emissions ranged from 30 to $75 \mathrm{Gg}$ ) and last $25 \%$ of gridded emissions (176 grids with emissions ranged $0-12 \mathrm{Gg}$ ). Moreover, the coefficient between $\mathrm{NO}_{2} \mathrm{VCDs}$ and gridded emissions for the 50-75\% interval in provincial inventory was 0.26 , while negative value $(-0.07)$ was calculated for MEIC, indicating that the emission estimation for areas with small and medium sources in the provincial inventory was more consistent with satellite observation. To better quantify the emissions at local scale, the results revealed the practical significance of careful investigation on individual small industrial sources that were usually identified as area sources due to lack of detailed information in national or regional inventories.

The comparisons between spatial distribution of VCDs and emissions should be interpreted cautiously, particularly for regions with relatively low values, as the signal-to-noise ratio in $\mathrm{OMI} \mathrm{NO}_{2}$ increases with decreased VCDs. Moreover, although summer data were applied to mitigate the effects of long lifetime of $\mathrm{NO}_{2}$ on pollution plume transport and chemical reaction, a non-linear relationship still exists 
between emissions and VCDs. More comparisons between $\mathrm{NO}_{2}$ from satellite observation and CTM are thus recommended when improved characterization of $\mathrm{NO}_{2}$ vertical distribution is available for the region.

\subsection{Evaluation of multi-scale inventories with CMAQ}

As mentioned in Sect. 2.5, anthropogenic emission inventories at provincial, regional, and national scales were applied to explore the impacts of emission input on the performance of a city-scale air quality simulation using CMAQ. With the original horizontal resolutions at $0.25 \times 0.25$ and $4 \times 4 \mathrm{~km}$, respectively, national (MEIC) and YRD regional inventories (Fu et al., 2013) were reallocated into the D3 of CCTM modeling at $3 \times 3 \mathrm{~km}$ (Fig. 1), consistent with our provincial inventory. The vertical and temporal distributions of the two inventories were assumed to be same as those of our provincial inventory, as indicated in Sect. 2.4. For the simulation with provincial inventory, emissions inside and outside Jiangsu in D3 were taken from the provincial inventory developed in this study and from the reallocated YRD regional inventory by Fu et al. (2013), respectively. Given the very limited data accessible on air quality for the province in 2012 , the available observation data at nine state-operated monitoring sites in Nanjing, including six urban sites (Xuanwumen (XWM), Shanxilu (SXL), Zhonghuamen (ZHM), Ruijinlu (RJL), Caochangmen (CCM), and Maigaoqiao (MGQ)) and three suburban sites (Pukou (PKS), Xianlin (XLS) and Olympic sports center (OSC)), were applied to evaluate the simulation performances with different emission inputs (see locations of the nine sites in Fig. 1).

The hourly ground concentrations from observation and CMAQ simulation for October 2012, expressed as the averages for all the monitoring sites in Nanjing, were compared and illustrated in Fig. S4 in the Supplement for $\mathrm{SO}_{2}, \mathrm{NO}_{2}$, ozone, and $\mathrm{PM}_{2.5}$. Even though all the simulations could reproduce well the time variation of each species, discrepancies existed when different anthropogenic emission inventories were used. The simulated $\mathrm{SO}_{2}$ and $\mathrm{NO}_{2}$ concentrations using the provincial inventory were notably lower than those with the other two inventories. In addition, simulations failed to catch the high $\mathrm{PM}_{2.5}$ and $\mathrm{O}_{3}$ concentrations for some heavy pollution episodes. For example, the average $\mathrm{PM}_{2.5}$ ground concentration during 21-23 and 28-29 October were simulated at 40 and $31 \mathrm{\mu g} \mathrm{m}^{-3}, 1.4$ and 3.2 times lower than observations, respectively. Two statistical indicators, normalized mean bias (NMB) and normalized mean error (NME), were applied to evaluate the model performance (Zhang et al., 2006), as summarized in Table 2. Among all the species, the best simulation performance was found for $\mathrm{NO}_{2}$, with the NMBs ranged within $\pm 30 \%$ for different emissions. In general, simulations using the provincial emission inventory performed notably better than those with national and regional ones for all the species. The NMEs were calculated at 47 , $33,44,52$ and the NMBs were calculated at $-10,-14,-25$,
$-43 \%$ for $\mathrm{SO}_{2}, \mathrm{NO}_{2}, \mathrm{O}_{3}, \mathrm{PM}_{2.5}$ respectively, comparable to previous US studies (Zhang et al., 2006; Wang et al., 2009). The result thus partly confirmed that air quality simulation at local or regional scales would be largely improved when detailed information on individual sources could be incorporated into the emission inventory. Improved model prediction for pollution event was also achieved with provincial inventory. Taking the pollution episode between 20:00 LT on 18 October and 17:00 LT on 19 October as an example, the observed $\mathrm{PM}_{2.5}$ concentration at CCM site kept increasing from 20:00 LT on 18th with the highest value reaching $114 \mu \mathrm{g} \mathrm{m}^{-3}$ at 02:00 LT on 19th. Simulated $\mathrm{PM}_{2.5}$ concentrations with provincial, regional, and national inventory at that time were 90,53 , and $45 \mu \mathrm{g} \mathrm{m}^{-3}$, respectively. The correlation coefficients between observation and simulations with the three inventories were calculated as $0.66,0.44$, and 0.30 during the episode, respectively, indicating the advantage of provincial inventory in the pollution event simulation.

Compared to primary pollutants $\mathrm{SO}_{2}$ and $\mathrm{NO}_{2}$, species with a strong secondary formation process $\left(\mathrm{PM}_{2.5}\right.$ and $\mathrm{O}_{3}$ in this case) were clearly under-predicted by CMAQ, no matter which inventory was applied. Lack of dust emissions in inventories might be one reason for underestimation of $\mathrm{PM}_{2.5}$. Moreover, as the significant components of $\mathrm{PM}_{2.5}$ in eastern China (Yang et al., 2011), secondary organic and inorganic aerosols might be under-predicted as a contributing factor to the weakness of chemical mechanisms in the version of CMAQ including the transformation of sulfate and the formation of secondary organic aerosols (Wang et al., 2009). For ozone simulation, better performance was found at suburban sites than urban sites, and the lower simulated concentrations than observation could possibly come from the underestimation in precursor VOC emissions. For example, the NMB was estimated at $-26 \%$ for PKS, where many chemical industrial plants were located nearby. In addition, the uncertainty of $\mathrm{NO}_{x}$ emission estimation might also contribute to the discrepancy. As indicated by the data from available continuous emission monitoring systems on Jiangsu's power plants, the $\mathrm{NO}_{x}$ emission factors of the power sector applied in current inventory might be overestimated for 2012 (unpublished).

The total emissions of $\mathrm{SO}_{2}$ and $\mathrm{NO}_{x}$ in Jiangsu estimated by Fu et al. (2013) was 1126 and $1257 \mathrm{Gg}$, i.e., 9 and $22 \%$ lower than the results of our provincial inventory, respectively. Using the regional inventory by Fu et al. (2013), much higher concentrations of $\mathrm{SO}_{2}$ and $\mathrm{NO}_{2}$ were simulated than were observed at the monitoring sites, with the NMBs calculated at 74 and $30 \%$, respectively. Even with larger emissions, in contrast, the NMBs for simulation with our provincial inventory were -10 and $-14 \%$, indicating lower simulated concentrations than were observed. This result implies the possible impacts of spatial distributions of emissions on air quality modeling. In regional inventories, densities of population and economic activities were generally applied to allocate large fraction of emissions, leading to particularly high emissions in urban areas, as the economy and 
Table 2. Model performance statistics for concentrations of given species from observation and CMAQ simulation using the national, regional and provincial inventories at the nine air quality monitoring sites in Nanjing for October 2012.

\begin{tabular}{|c|c|c|c|c|c|c|}
\hline \multirow[t]{2}{*}{ Pollutants } & \multicolumn{2}{|c|}{ National (MEIC) } & \multicolumn{2}{|c|}{ Regional (Fu et al., 2013) } & \multicolumn{2}{|c|}{ Provincial (this work) } \\
\hline & NMB & NME & NMB & NME & NMB & NME \\
\hline $\mathrm{SO}_{2}$ & $48.45 \%$ & $76.53 \%$ & $74.08 \%$ & $95.04 \%$ & $-9.97 \%$ & $47.49 \%$ \\
\hline $\mathrm{NO}_{2}$ & $21.02 \%$ & $35.99 \%$ & $29.84 \%$ & $43.45 \%$ & $-14.47 \%$ & $33.22 \%$ \\
\hline $\mathrm{O}_{3}$ & $-65.55 \%$ & $68.57 \%$ & $-53.93 \%$ & $61.59 \%$ & $-24.98 \%$ & $44.29 \%$ \\
\hline $\mathrm{PM}_{2.5}$ & $-51.63 \%$ & $55.32 \%$ & $-49.16 \%$ & $56.00 \%$ & $-43.64 \%$ & $51.81 \%$ \\
\hline
\end{tabular}

Note: NMB and NME were calculated using following equations $(P$ and $O$ indicate the results from modeling prediction and observation, respectively): NMB $=\frac{\sum_{i=1}^{n}\left(P_{i}-O_{i}\right)}{\sum_{i=1}^{n} O_{i}} \times 100 \% ; \mathrm{NME}=\frac{\sum_{i=1}^{n}\left|P_{i}-O_{i}\right|}{\sum_{i=1}^{n} O_{i}} \times 100 \%$.

population was generally centralized in the downtown area. Given that all the monitoring sites in Nanjing are located in urban or suburban areas, air quality simulation using regional emission inventory was thus liable to over-predict the ground concentrations at those sites.

Spatial distributions of the monthly mean for simulated concentrations using national, regional, and provincial inventories were plotted for $\mathrm{SO}_{2}, \mathrm{NO}_{2}, \mathrm{PM}_{2.5}$, and $\mathrm{O}_{3}$ in Fig. 6, and the differences between simulations with varied emissions were shown in Fig. 7. As the MEIC emissions were greatly averaged when they were directly downscaled from $0.25^{\circ} \times 0.25^{\circ}$ to $3 \times 3 \mathrm{~km}$, the simulated high concentrations using MEIC were broadly distributed in the modeling domain and commonly located in the downtown area (as indicated in Fig. S1), with the large emitters hardly identified (Fig. 6a). For results using the regional and provincial inventories, there were several grids with notably outstanding simulated concentrations, indicating the existence of large emitters (Fig. 6b and c), and differences with the simulation using MEIC were induced (Fig. 7a and b). As shown in Fig. 7c, moreover, clear differences were also detected between simulations using regional and provincial inventories, implying the discrepancy in allocations of high emissions between the two inventories. With the locations of large power, iron and steel, and cement plants incorporated, the YRD regional emission inventory by Fu et al. (2013) allocated a large fraction of emissions from industries as area sources. In contrast, the emissions from most power and industrial plants were calculated based on source-specific information and were precisely allocated in the provincial inventory, avoiding in particular the emission overestimation in the downtown area. In addition, the simulated $\mathrm{NO}_{2}$ and $\mathrm{O}_{3}$ concentrations for regions outside Jiangsu (i.e., Shanghai and part of Zhejiang and Anhui), measured using the provincial inventory, were $22 \%$ lower and $40 \%$ higher on average than those using the regional one, respectively (Fig. 7c), although the same emissions (Fu et al., 2013) were used outside Jiangsu for the two inventories. The result indicates that both local and regional emissions were important for the simulations of secondary pollutants like $\mathrm{O}_{3}$. Total VOC emissions for Jiangsu were estimated at $1740 \mathrm{Gg}$ in MEIC, slightly higher than those in the regional $(1659 \mathrm{Gg})$ and provincial inventory $(1617 \mathrm{Gg})$, while the simulated monthly mean $\mathrm{O}_{3}$ concentrations within Jiangsu using MEIC were notably lower than those using the latter two emissions. Categorized by CB05, differences in chemical compositions of VOCs could be found in the three inventories, attributed to the varied source contributions to VOC emissions and to the different source profiles used in emission speciation (Zhao et al., 2017). For example, the emissions of ethane (ETH) and ethanol (ETHA) with relatively high ozone-formation potential in the provincial inventory were 44 and $209 \%$ higher than those in MEIC, respectively. Therefore, the total emission amount, spatial distribution of emissions, and chemical compositions of precursors are all crucial to the accuracy of ozone simulations, and further analysis on those factors is suggested.

\subsection{Improved $\mathrm{SO}_{2}$ simulation under special meteorological condition}

To further examine the simulated concentration response to varied emission inputs at local scale, the simulated $\mathrm{SO}_{2}$ concentrations using national, regional, and provincial inventories were compared with observation at three monitoring sites in downtown Nanjing (XWH, RJL and ZHM) for 614 October 2012, as illustrated in Fig. 8. The simulated concentrations using our provincial inventory were the most consistent with observation, while apparent overestimation was found for the simulations using national or regional inventories. At 20:00 LT on 9 October, in particular, the $\mathrm{SO}_{2}$ concentrations were observed at 33,12 , and $14 \mu \mathrm{g} \mathrm{m}^{-3}$ at XWH, RJL, and ZHM sites, respectively, while the simulated concentrations were respectively simulated at 205, 246 and $228 \mu \mathrm{g} \mathrm{m}^{-3}$ using MEIC (i.e., 5-19 times higher than the observation). The analogue numbers with regional inventory by $\mathrm{Fu}$ et al. (2013) even reached 550,477 , and $476 \mu \mathrm{g} \mathrm{m}^{-3}$, i.e., 15-38 times higher than observation. Although concentrations remained over-predicted, better performance was 

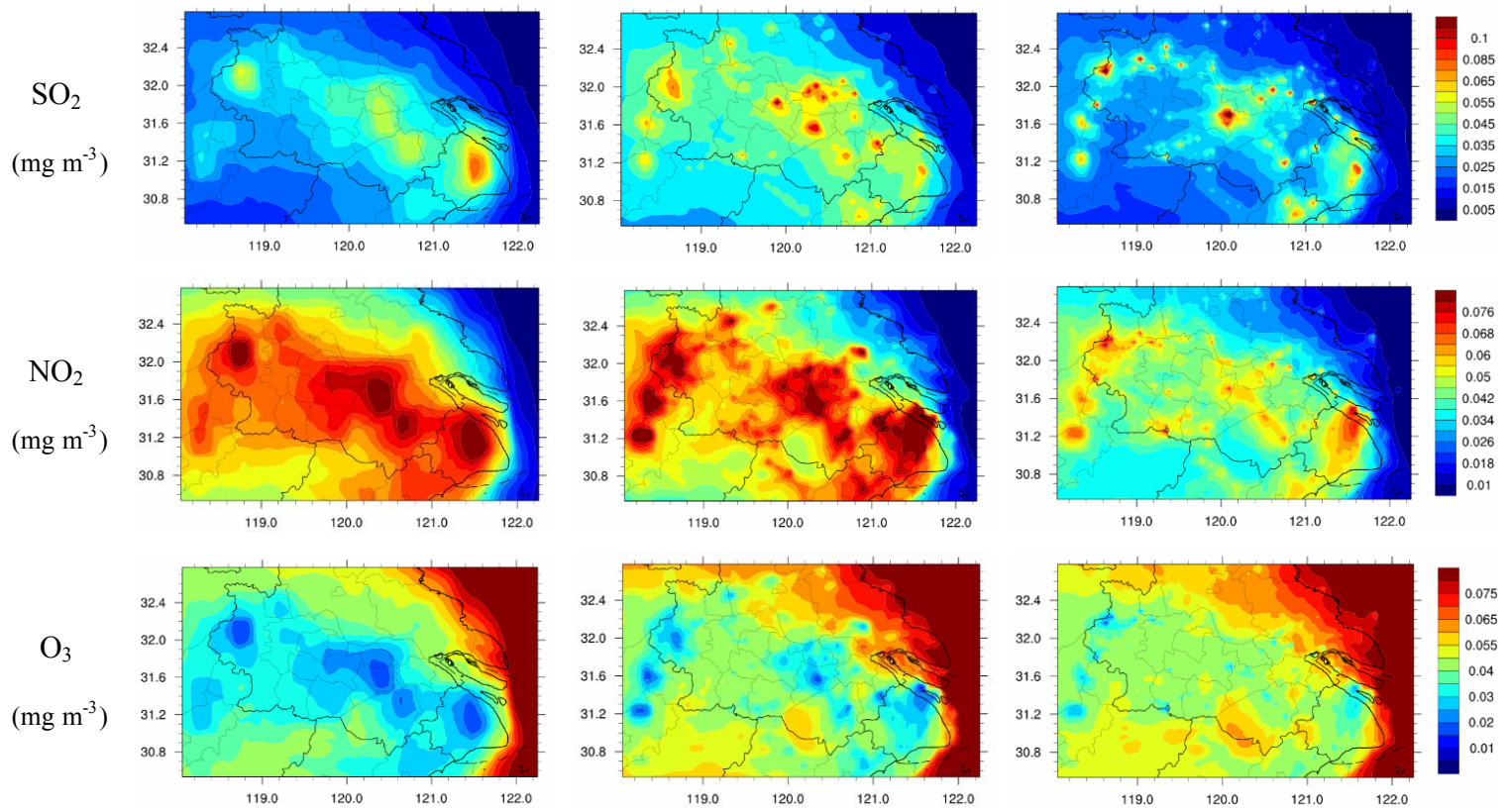

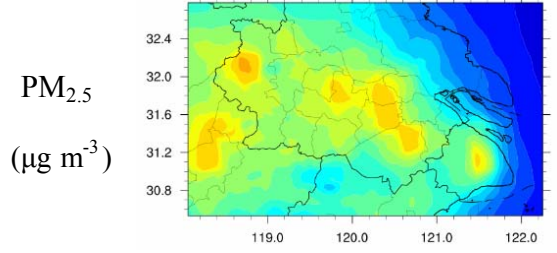

(a) National (MEIC)

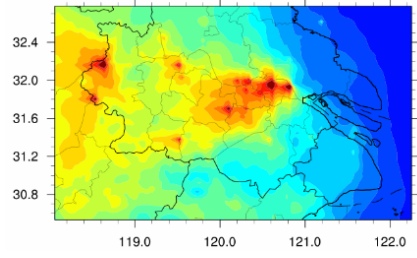

(b) Regional (Fu et al., 2013)

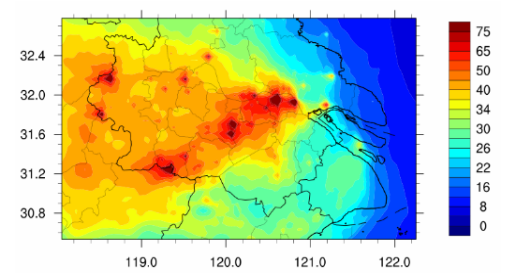

(c) Provincial (this work)

Figure 6. Spatial distributions of the monthly means of simulated $\mathrm{SO}_{2}, \mathrm{NO}_{2}, \mathrm{PM}_{2.5}$, and $\mathrm{O}_{3}$ concentrations using the national, regional, and provincial emission inventories for October 2012.

achieved when the improved provincial inventory was used, implying its advantage prior to national or regional ones in the high-resolution air quality modeling. The discrepancies in emissions and the simulated meteorological conditions, including wind velocity and height of planetary boundary layer $(\mathrm{PBL})$, were inspected in order to understand the very high concentrations from simulation.

Figure S5 in the Supplement shows the simulated wind fields from 14:00 LT on 9 October to 05:00 LT on 10 October. From 14:00 LT on 9 October, WS10 in downtown Nanjing started to decline gradually and reached the minimum of $0.22 \mathrm{~m} \mathrm{~s}^{-1}$ at 20:00 LT, which is simply not beneficial for the horizontal convection of atmosphere. In addition, the monthly average of PBL height at XWH was simulated at $485 \mathrm{~m}$ during the day and $140 \mathrm{~m}$ during the night in October. From 17:00 LT on 9th to 10:00 LT on 10 October, however, the average PBL height decreased to $39 \mathrm{~m}$, with the minimum simulated at $32 \mathrm{~m}$ at 23:00 LT on 9 October, seriously restricting the vertical diffusion of pollutants. Under the meteorological condition that horizontal and vertical movement of atmosphere is limited, primary pollutants from large emit- ters would be easily accumulated over time, possibly leading to high concentrations for areas close to the emission sources. In this case, therefore, the simulated $\mathrm{SO}_{2}$ concentrations would be largely influenced by the emissions from local and nearby sources, as discussed below.

The total $\mathrm{SO}_{2}$ emissions in Nanjing were estimated at $141 \mathrm{Gg}$ in the provincial inventory, 2 and $7 \%$ higher than those of national and regional ones respectively. Without a big difference in total amount, large discrepancies in spatial distribution existed in those inventories, particularly at high horizontal resolution, as shown in Fig. 9. Downscaled from $0.25^{\circ} \times 0.25^{\circ}$ to $3 \times 3 \mathrm{~km}$, grids with similar emissions were clustered for MEIC and spatial variations in emissions could hardly be detected other than the hotspot in the downtown area (Fig. 9c). Notably lower emissions in downtown Nanjing were found in our provincial inventory than the regional one (Fig. 9a and b). In addition, the grid with maximum $\mathrm{SO}_{2}$ emissions $(15.7 \mathrm{Gg})$ in the provincial inventory was in the northwestern area of Nanjing where a super power plant was located, labeled as the black star (point A) in Fig. 9. As a comparison, the grid with the maximum $\mathrm{SO}_{2}$ emissions in 

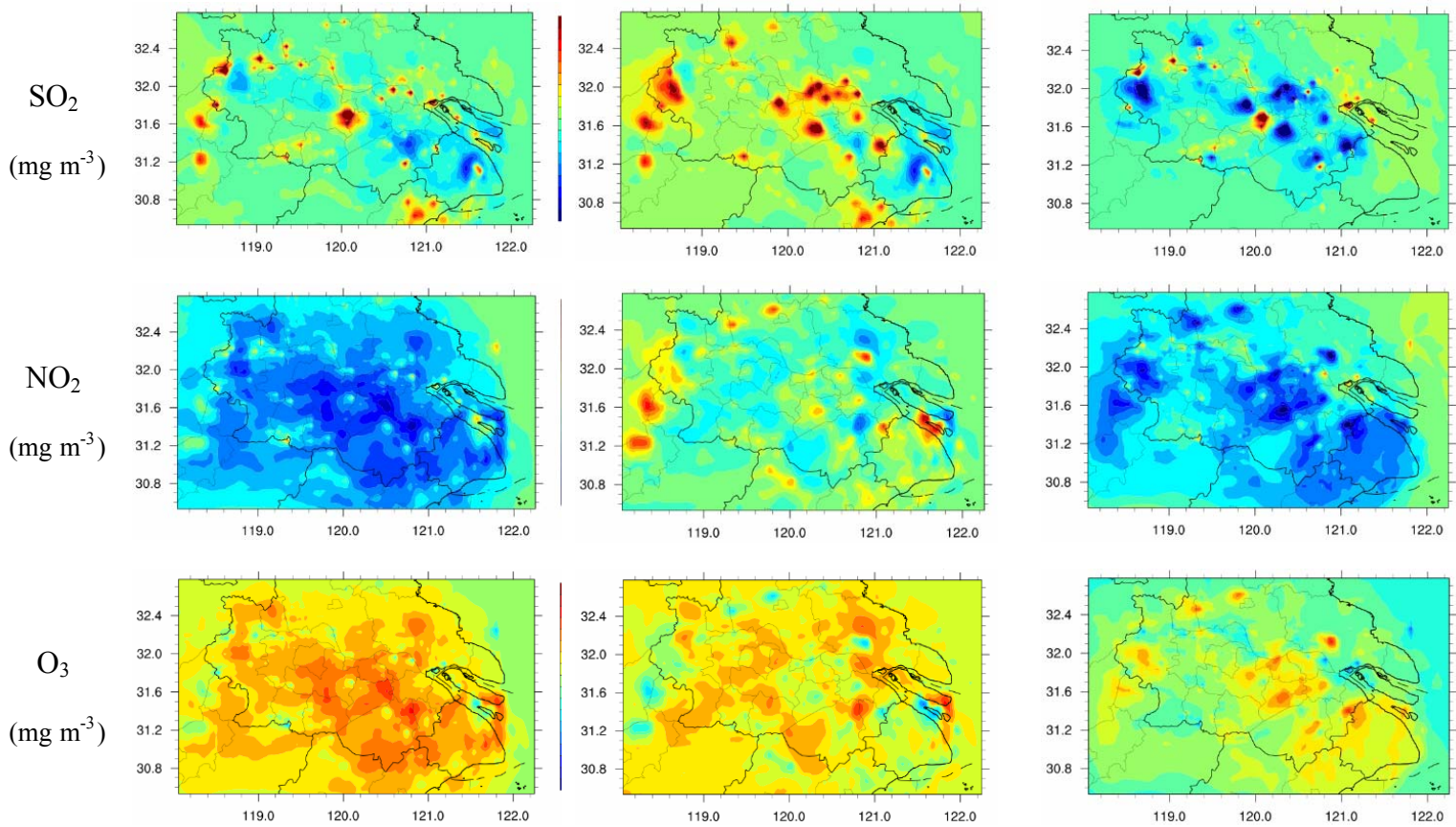

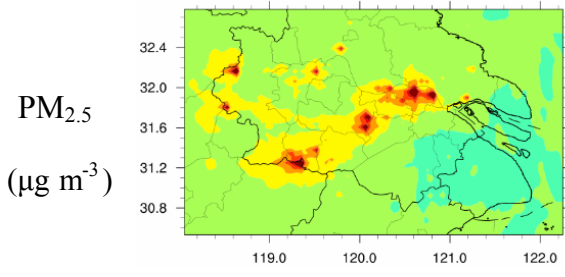

(a) Provincial - national

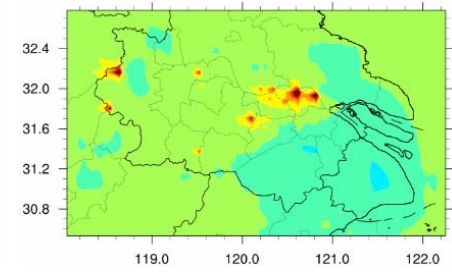

(b) Regional - national

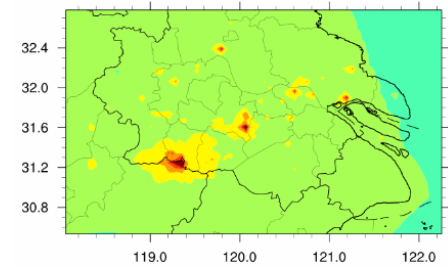

(c) Provincial - regional

Figure 7. The differences in the monthly means of simulated $\mathrm{SO}_{2}, \mathrm{NO}_{2}, \mathrm{PM}_{2.5}$, and $\mathrm{O}_{3}$ concentrations using different emission inventories: (a) provincial-national; (b) regional-national; and (c) provincial-regional. The black star A and triangle B referred to the locations of grids with maximum $\mathrm{SO}_{2}$ emissions in provincial and regional inventory.

the regional inventory, labeled as the black triangle (point B) in Fig. 9, was adjacent to the location of point A, and its emissions were calculated to be only $28 \%$ of the result in the provincial one. Given no other super-emitters located nearby, we expected that the discrepancy resulted mainly from the varied emission estimation and positioning for the same power plant in the two inventories. According to on-site survey, only one unit out of two for the plant was installed with FGD, and the $\mathrm{SO}_{2}$ emissions of the plant were estimated to be $13.6 \mathrm{Gg}$, accounting for $87 \%$ of the total emissions in the grid. In contrast, a higher FGD installation rate at $85 \%$ was uniformly assumed for the power sector in the regional inventory by Fu et al. (2013), leading to possible underestimation in emissions for the plant. The comparison implied that detailed information compiled from individual plants was crucial for estimation and spatial distribution of pollutant emissions at local scales. $\mathrm{SO}_{2}$ emissions at given monitoring sites were extracted from the gridded national, regional, and provincial inventories and summarized in Table 3. As most large $\mathrm{SO}_{2}$ emitters were located in suburban or rural areas, relatively small emissions were found in the provincial inventory for downtown Nanjing where the monitoring sites were located. As large fractions of emissions were allocated by the density of economy and population, however, the $\mathrm{SO}_{2}$ emissions in the regional emission inventory were estimated at $1791,1721,1918$, and $1635 \mathrm{Mg}$ at XWH, RJL, ZHM, and CCM sites, which were 4-5 times higher than those of our provincial inventory. In MEIC, the emissions at XWH, RJL, ZHM, and MGQ sites were identically estimated at $1298 \mathrm{Mg}$ from the downscaling approach, and they were also much larger than those in the provincial inventory. Given the unfavorable condition of pollutant transport for 9-10 October, the overestimation in local emissions around the downtown monitoring sites in the national and regional inventories thus lead to very high simulated concentrations, while the results using the provincial one were much more reasonable. The comparison confirms the benefits of precise quantification of emissions for local air quality modeling. 

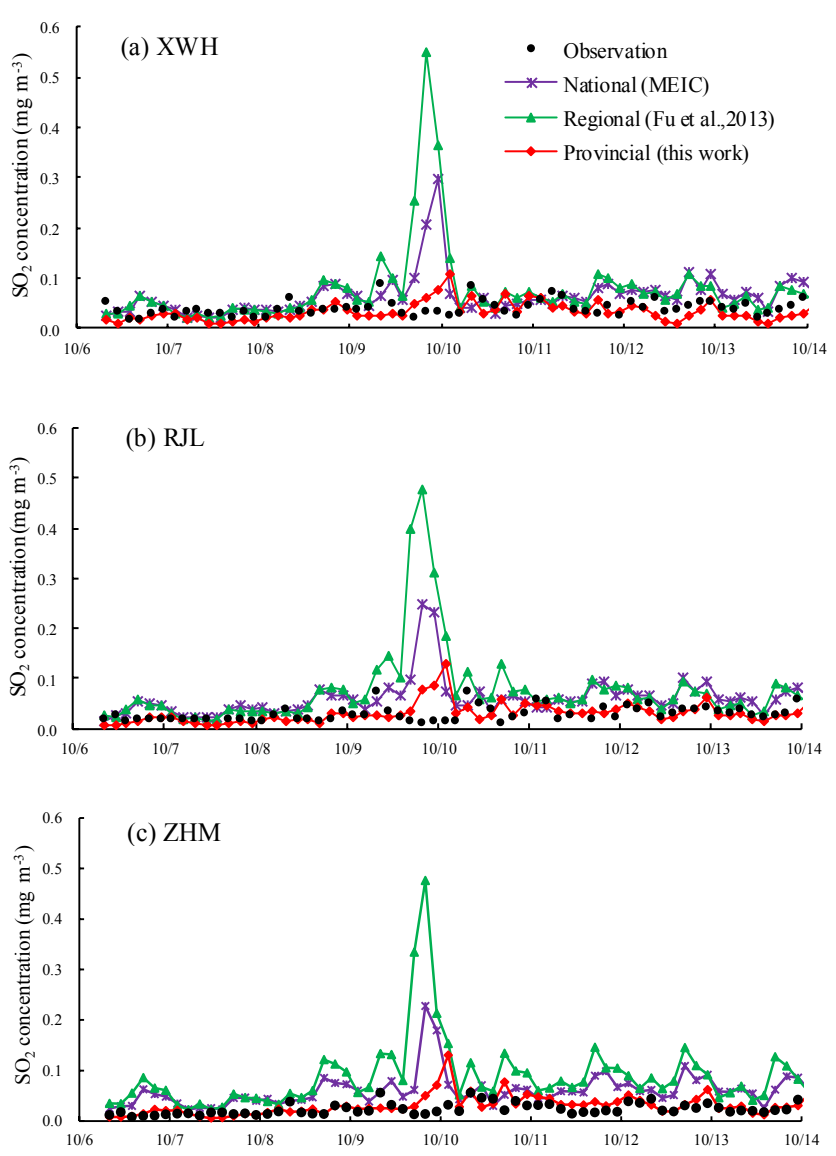

Figure 8. The observed and simulated hourly $\mathrm{SO}_{2}$ concentrations (expressed with $3 \mathrm{~h}$ intervals) using the national, regional, and provincial inventories at XWH (a), RJL (b), and ZHM (c) from 6 to 13 October 2012.

Table 3. The annual $\mathrm{SO}_{2}$ emissions estimated in three inventories at given air quality monitoring sites in downtown Nanjing.

\begin{tabular}{lrrr}
\hline $\mathrm{SO}_{2} / \mathrm{Mg}$ & $\begin{array}{r}\text { National } \\
\text { (MEIC) }\end{array}$ & $\begin{array}{r}\text { Regional } \\
\text { (Fu et al., 2013) }\end{array}$ & $\begin{array}{r}\text { Provincial } \\
\text { (this work) }\end{array}$ \\
\hline $\mathrm{XWH}$ & 1297.5 & 1790.9 & 411.0 \\
$\mathrm{RJL}$ & 1297.5 & 1720.8 & 303.1 \\
$\mathrm{ZHM}$ & 1297.5 & 1918.3 & 396.2 \\
$\mathrm{CCM}$ & 928.6 & 1635.3 & 371.8 \\
$\mathrm{MGQ}$ & 1297.5 & 478.6 & 395.0 \\
\hline
\end{tabular}

Despite significant improvement, overestimation in $\mathrm{SO}_{2}$ concentrations still existed in the simulation with our provincial inventory, attributed possibly to the error of meteorology modeling. Here we selected the XWH site as an example to conduct the back trajectory analysis using HYSPLIT model (http://ready.arl.noaa.gov/HYSPLIT.php). Shown in Fig. S6 in the Supplement, the air mass reaching the site at $50 \mathrm{~m}$ altitude came mainly from the northeast at 23:00 LT on 9 October. However, it was inconsistent with WRF modeling re- sults, which indicated the dominating wind was from the northwest $\left(150-170^{\circ}\right)$ at that time. As mentioned above, a big power plant was located northwest of XWH (Fig. 9a), and the site might partly be influenced by the large emissions from the plant, and enhanced concentrations would then be obtained when the northwest wind was simulated.

\section{Sensitivity analysis of $\mathrm{PM}_{2.5}$ and ozone formation in Nanjing}

Using the improved provincial inventory, the sensitivity of $\mathrm{PM}_{2.5}$ and $\mathrm{O}_{3}$ concentrations to emissions were further analyzed through the brute force method (BFM, Dunker et al., 1996). For $\mathrm{PM}_{2.5}$, four simulation scenarios were designed: Scenario B (the base case) in which the emissions from all types of sources are included, and Scenarios S1, S2, and S3 in which the pollutant emissions of power, iron and steel, and cement plants in D3 were zeroed out, respectively. The changes in simulated $\mathrm{PM}_{2.5}$ ground concentrations in $\mathrm{S} 1, \mathrm{~S} 2$, and S3 compared to those in the base case for October 2012 are illustrated in Fig. S7 in the Supplement. The average concentration increments in urban areas of Nanjing caused by power, iron and steel, and cement plants were calculated respectively at 3,11 , and $7 \mu \mathrm{g} \mathrm{m}^{-3}$, accounting for 6,26 , and $16 \%$ of the monthly mean $\mathrm{PM}_{2.5}$ concentrations, and the maximum increments within the domain reached 10, 72, and $25 \mu \mathrm{g} \mathrm{m}^{-3}$, respectively. Given the tiny emission fraction of the power sector for primary $\mathrm{PM}_{2.5}$ (4\% in Jiangsu Province) and the small share in the ground layers $(15 \%$ for first plus second vertical layers), its contribution to $\mathrm{PM}_{2.5}$ ground concentration was notably lower than those of both iron and steel production and cement production. Summarized in Table 4 are the contributions of power, iron and steel, and cement sectors to monthly mean $\mathrm{PM}_{2.5}$ at the nine monitoring sites in Nanjing in October 2012. The contributions of the three sectors to average $\mathrm{PM}_{2.5}$ concentrations at all the sites were estimated at 8,13 , and $9 \%$, respectively. Since all the sites are located in the urban or suburban areas, the estimated $\mathrm{PM}_{2.5}$ contributions at individual sites varied slightly from one to another. Besides monthly mean, the hourly maximum and minimum contributions are provided as well in Table 4 . The largest hourly contributions from power, iron and steel, and cement plants to $\mathrm{PM}_{2.5}$ concentrations were $65 \%$ at PKS, $89 \%$ at MGQ and $58 \%$ at both CCM and OCS, respectively. The contributions became negative at 14:00 LT on 26 October with average $\mathrm{PM}_{2.5}$ concentration of all the sites observed as $164 \mu \mathrm{g} \mathrm{m}^{-3}$ and simulated as $151 \mu \mathrm{g} \mathrm{m}^{-3}$ under the base case, i.e., increased particle concentrations were simulated at the moment when emissions from a given sector were turned off. The result indicated, on the one hand, the relatively high uncertainty of simulation for heavy PM pollution episodes dominated by regional transport. On the other hand, as the simulated increments were mostly from the elevated sulfate $\left(\mathrm{SO}_{4}^{2-}\right)$, nitrate $\left(\mathrm{NO}_{3}^{-}\right)$, and ammonium $\left(\mathrm{NH}_{4}^{+}\right)$, the negative 

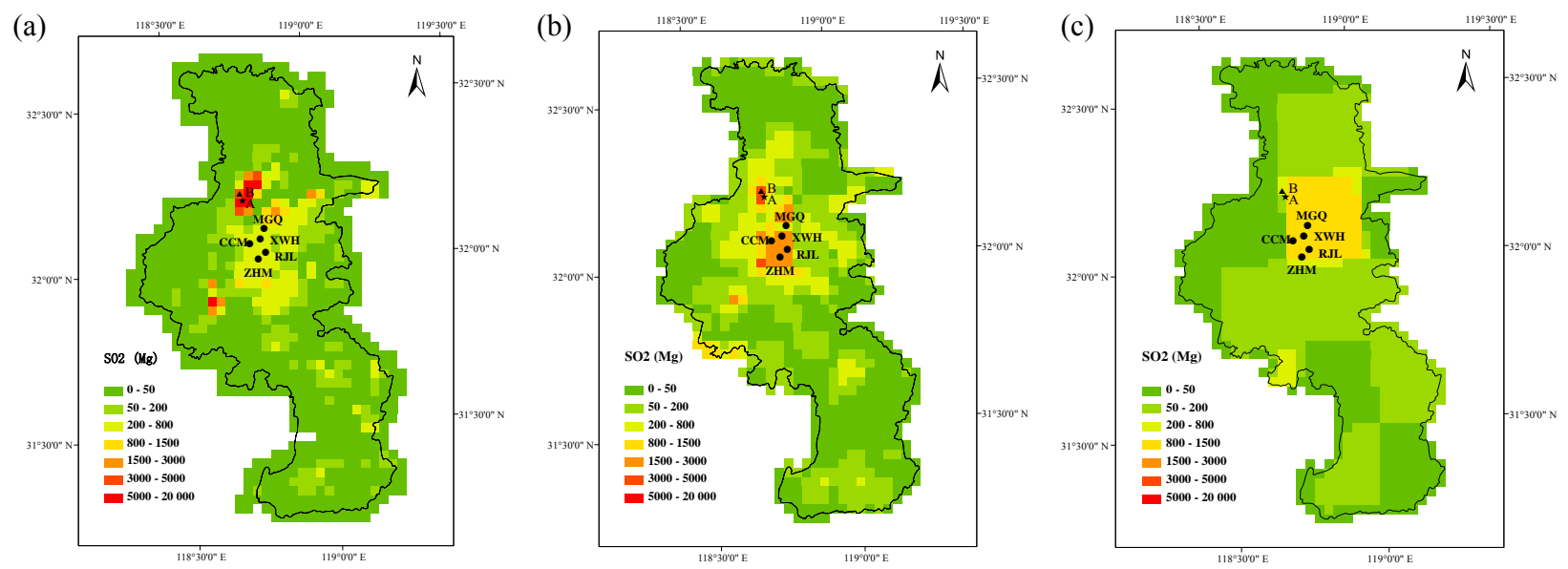

Figure 9. Spatial distributions of the estimated $\mathrm{SO}_{2}$ emissions in Nanjing at the resolution of $3 \times 3 \mathrm{~km}$ in the provincial (a), regional (b), and national emission inventory (c). The black dots indicate the locations of given air quality monitoring sites. The black star (point A) indicates the location of the power plant with the largest $\mathrm{SO}_{2}$ emissions estimated in the provincial inventory. The black triangle (point $\mathrm{B}$ ) indicates the speculated position of the same power plant in the regional inventory.

Table 4. The monthly mean contributions of power, iron and steel, and cement plants to the $\mathrm{PM}_{2.5}$ concentrations at the air quality monitoring sites in Nanjing in October 2012.

\begin{tabular}{|c|c|c|c|c|c|c|c|c|c|}
\hline \multirow[t]{2}{*}{ Monitoring site } & \multicolumn{3}{|c|}{ Contri. of power $(\%)$} & \multicolumn{3}{|c|}{ Contri. of iron and steel (\%) } & \multicolumn{3}{|c|}{ Contri. of cement (\%) } \\
\hline & Max. & Min. & Ave. & Max. & Min. & Ave. & Max. & Min. & Ave. \\
\hline XWH/SXL & 52 & -6 & 8 & 82 & -2 & 14 & 43 & -1 & 8 \\
\hline RJL & 42 & -6 & 7 & 79 & 0 & 11 & 44 & 0 & 9 \\
\hline ZHM & 44 & -5 & 7 & 71 & -3 & 12 & 48 & 0 & 9 \\
\hline $\mathrm{CCM}$ & 32 & -8 & 7 & 83 & -4 & 13 & 58 & -5 & 8 \\
\hline MGQ & 58 & -5 & 9 & 89 & -2 & 8 & 35 & -5 & 7 \\
\hline XLS & 35 & -5 & 7 & 67 & -3 & 10 & 57 & 0 & 10 \\
\hline PKS & 65 & -6 & 7 & 77 & -1 & 11 & 45 & -1 & 7 \\
\hline OCS & 33 & -7 & 7 & 87 & 0 & 12 & 58 & 0 & 8 \\
\hline
\end{tabular}

Note: Max., min., ave., and contri. indicate maximum, minimum, average, and contribution, respectively.

contributions might also be caused by the complex chemical mechanisms of $\mathrm{SO}_{2}$ and $\mathrm{NO}_{x}$ reactions with $\mathrm{NH}_{3}$ under the $\mathrm{NH}_{3}$-rich conditions in YRD (Wang et al., 2011). Intensive real-time observation on chemical composition of $\mathrm{PM}_{2.5}$ is thus recommended to better capture and analyze the processes.

To explore the sensitivity of $\mathrm{O}_{3}$ formation to its precursor emissions, two scenarios were set besides the base case: the VOC-abatement scenario with $50 \%$ reduction of all anthropogenic VOC emissions in D3 (Scenario P1), and the $\mathrm{NO}_{x}$ abatement scenario with $50 \%$ reduction of $\mathrm{NO}_{x}$ in $\mathrm{D} 3$ (Scenario P2). Shown in Fig. S8 in the Supplement are the average $\mathrm{O}_{3}$ concentration changes from 6 to 15 October. The simulated $\mathrm{O}_{3}$ average concentration from 11:00 to 17:00 LT declined significantly under Scenario P1, with the maximum reduction at $54 \mu \mathrm{g} \mathrm{m}^{-3}$ (Fig. S8a) within D3, and changes in the downwind region were greater than the upwind. In contrast, the concentrations were generally enhanced under P2 with the maximum increment at $19 \mu \mathrm{g} \mathrm{m}^{-3}$. A similar variation pattern was found for $1 \mathrm{~h}$ maximum $\mathrm{O}_{3}$ concentration in Fig. S8b and monthly mean concentration in Fig. S8c. The $1 \mathrm{~h}$ maximum $\mathrm{O}_{3}$ concentrations in most downwind areas of Shanghai and southern Jiangsu decreased $10-20 \mu \mathrm{g} \mathrm{m}^{-3}$ with the reduction in VOC emissions, and the concentrations would generally increase $10-30 \mu \mathrm{g} \mathrm{m}^{-3}$ with the $\mathrm{NO}_{x}$ reduction. The similar patterns of $\mathrm{O}_{3}$ concentration variation in urban and downwind areas in D3 under P1 or P2 scenario indicated that the $\mathrm{O}_{3}$ formation was VOC-limited in all those areas in southern Jiangsu. Therefore, VOC emission abatement could be effective for $\mathrm{O}_{3}$ pollution control in southern Jiangsu, while $\mathrm{NO}_{x}$ abatement might aggravate the pollution in autumn.

The temporal changes in the simulated $\mathrm{O}_{3}$ concentrations between the P1/P2 and base scenarios at urban (XWH, SXL, RJL, MGQ, ZHM, and CCM) and suburban sites (XLS, OCS, and PKS) in Nanjing were illustrated for 6-16 October 
(a)

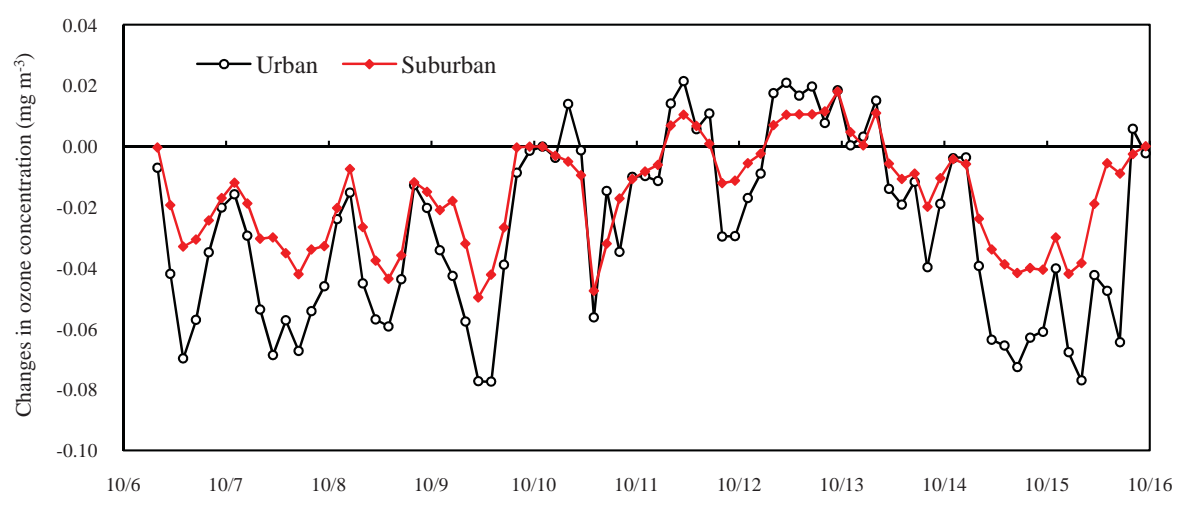

(b)

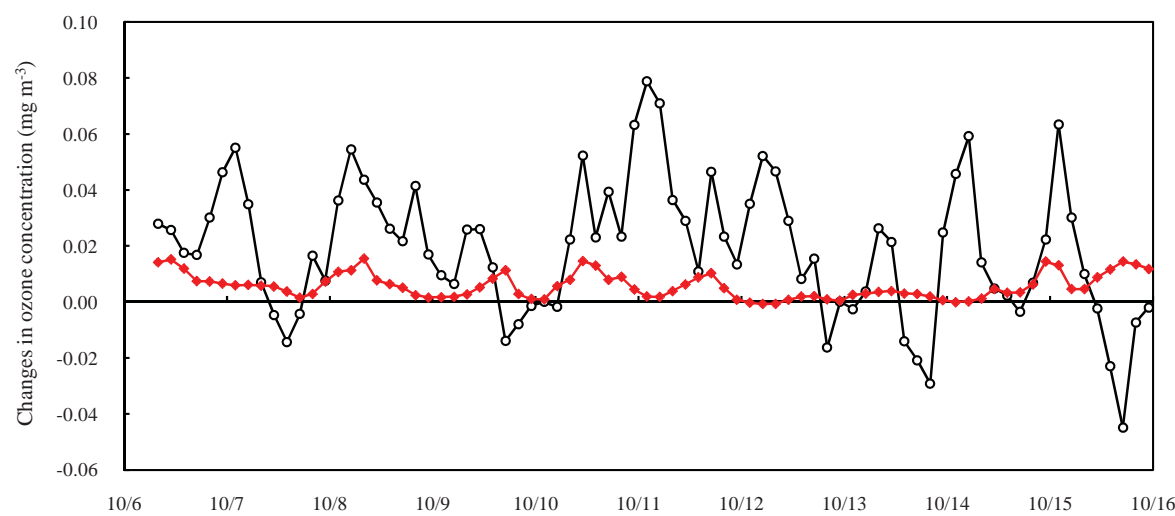

Figure 10. The changes in simulated $\mathrm{O}_{3}$ concentrations at urban (XWH, SXL, RJL, MGQ, ZHM, and CCM) and suburban (XLS, OSC, and PKS) air quality monitoring sites in Nanjing under P1 (a) and P2 (b) scenarios, compared to the base case for 6-16 October 2012.

in Fig. 10. Simulated $\mathrm{O}_{3}$ concentrations at urban and suburban sites were generally decreased once the VOC emissions declined and the maximum hourly reduction reached 77.3 and $49.6 \mu \mathrm{g} \mathrm{m}^{-3}$, respectively. In contrast, concentrations were elevated with the $\mathrm{NO}_{x}$ emission reduction and the maximum growths were 78.7 and $15.4 \mu \mathrm{g} \mathrm{m}^{-3}$, respectively. Under a VOC-limited regime, in general, the $\mathrm{O}_{3}$ concentration would be only slightly sensitive to the change of $\mathrm{NO}_{x}$ unless it was rich enough to turn to the negative correlation with $\mathrm{O}_{3}$. Therefore, due to the intensive $\mathrm{NO}_{x}$ emissions from on-road transportation in downtown Nanjing, the variations of $\mathrm{O}_{3}$ concentrations in $\mathrm{P} 2$ scenario at urban monitoring sites were notably greater than those at suburban sites. It should be acknowledged that uncertainty existed in the sensitivity analysis, as the brute force method ignores the nonlinearity of $\mathrm{O}_{3}$ response to the changes of precursor emissions. With techniques other than brute force, e.g., ozone source apportionment (OSAT, Li et al., 2012) or tagged species method (Zhang et al., 2011), the nonlinearity mechanism of $\mathrm{O}_{3}$ formation could be taken into account. Comparisons between results with different methods are further recommended for the region.

\section{Conclusions}

The bottom-up approach was applied to develop a highresolution emission inventory for Jiangsu, with substantial detailed information on local sources incorporated. Key parameters relevant to emission estimation were examined and revised plant by plant, including geographic position, energy consumption, and removal efficiencies of APCD from various data sources and on-site surveys on large emitters. Compared to previous studies, the emission fractions of point sources were significantly enhanced, except for $\mathrm{NH}_{3}$ and $\mathrm{OC}$, which are mainly from agricultural activities and biomass open burning, respectively. As lower removal efficiencies of dust collectors were obtained from local investigation, larger primary PM emissions were estimated in our provincial inventory than other national or regional ones. Moreover, clear discrepancies existed in spatial distribution of industrial $\mathrm{PM}_{2.5}$ emissions between this work and the national inventory MEIC, indicating the uncertainty of emission downscaling from coarse horizontal resolution. The spatial distribution of $\mathrm{NO}_{x}$ emissions in the provincial inventory was more consistent with summer tropospheric $\mathrm{NO}_{2}$ VCDs observed 
from OMI than that of MEIC, particularly for the emissions from small and medium industrial plants. The WRF-CMAQ air quality modeling system was set up to evaluate the reliability and improvement of the provincial emission inventory by comparing the simulation performance with that using a national (MEIC) and regional one. Among the three inventories, the best agreement was found between the observation and simulation with the provincial one for all the concerned species at the nine monitoring sites in Nanjing, while underestimation existed particularly for $\mathrm{PM}_{2.5}$ and $\mathrm{O}_{3}$, which were strongly influenced by secondary formation. Under the unfavorable meteorology of pollutant transport, extremely high $\mathrm{SO}_{2}$ concentrations were simulated using the regional and national inventories, while the results using the provincial one were much closer to the observation. The results indicated the advantage of improved estimation and spatial distribution of emissions on air quality modeling at regional or local scales. The improved provincial inventory was further applied for the sensitivity analysis on $\mathrm{PM}_{2.5}$ and $\mathrm{O}_{3}$ formation using BFM simulation, and provided the preliminary results for the policy-making of regional haze and photochemical pollution control in southern Jiangsu.

Limitations remained in the current inventory. Attributed to unavailability of detailed information, the weekly and hourly variation of emissions could not be fully tracked for each city, and the vertical distribution of emissions by sector, depending mainly on the stack height, temperature, and flow of flue gas, could not be accurately determined. Instead, empirical data from previous work (Li et al., 2011; L. Wang et al., 2010, 2014) had to be applied, which might be inconsistent with the reality. In addition, some sources were not included in the current inventory (e.g., fugitive dust emissions from construction sites and road transportation), resulting from lack of reliable data and thereby potentially causing large uncertainties in the emission estimation at provincial level. Finally, the effects of source profiles on air quality modeling (e.g., the speciation of primary $\mathrm{PM}_{2.5}$ and VOC) were not fully evaluated. As they are important for the formation of $\mathrm{O}_{3}$ and secondary particles, more investigations on typical sources and evaluation through chemistry transport modeling are suggested in the future.

\section{Data availability}

The gridded emissions of air pollutants for Jiangsu province 2012 at a horizontal resolution of $3 \times 3 \mathrm{~km}$ can be downloaded at http://www.airqualitynju.com/En/Data/List/ Datadownload.

\section{The Supplement related to this article is available online at doi:10.5194/acp-17-211-2017-supplement.}

Acknowledgements. This work was sponsored by the Natural Science Foundation of China (91644220 and 41575142), Natural Science Foundation of Jiangsu (BK20140020), Ministry of Science and Technology of China (2016YFC0201507), Jiangsu Science and Technology Support Program (SBE2014070918), and Special Research Program of Environmental Protection for Commonwealth (201509004). We would like to acknowledge Litao Wang from Hebei University of Engineering, Jia Xing from Tsinghua University for the assistance in CMAQ model, and Xiao Fu from Tsinghua University for providing the emission inventory for the Yangtze River Delta region, China. Thanks also go to two anonymous reviewers for their very valuable comments to improve this work.

Edited by: G. Carmichael

Reviewed by: two anonymous referees

\section{References}

Baker, K., Johnson, M., and King, S.: Meteorological modeling performance summary for application to $\mathrm{PM}_{2.5} /$ haze/ozone modeling projects, Lake Michigan Air Directors Consortium, Midwest Regional Planning Organization, Des Plaines, Illinois, USA, 57 pp., 2004.

Bo, Y., Cai, H., and Xie, S. D.: Spatial and temporal variation of historical anthropogenic NMVOCs emission inventories in China, Atmos. Chem. Phys., 8, 7297-7316, doi:10.5194/acp-8-72972008, 2008.

Boersma, K. F., Eskes, H. J., Dirksen, R. J., van der A, R. J., Veefkind, J. P., Stammes, P., Huijnen, V., Kleipool, Q. L., Sneep, M., Claas, J., Leitão, J., Richter, A., Zhou, Y., and Brunner, D.: An improved tropospheric $\mathrm{NO}_{2}$ column retrieval algorithm for the Ozone Monitoring Instrument, Atmos. Meas. Tech., 4, 19051928, doi:10.5194/amt-4-1905-2011, 2011.

Cai, H. and Xie, S. D.: Estimation of vehicular emission inventories in China from 1980 to 2005, Atmos. Environ., 41, 8963-8979, 2007.

Cheng, Z., Chen, C. H., Huang, C., Huang, H. Y., Li, L., and Wang, H. L.: Trans-boundary. primary air pollution between cities in the Yangtze River Delta, Acta Sci. Circum., 31, 686-694, 2011 (in Chinese).

Dong, Y. Q., Chen, C. H., Huang, C., Wang, H. L., Li, L., Dai, P., and Jia, J. H.: Anthropogenic emissions and distribution of ammonia in Yangtze River Delta, Acta Sci. Circum., 29, 16111617, 2009 (in Chinese).

Dunker, A. M., Morris, R. E., Pollack, A. K., Schleyer, C. H., and Yarwood, G.: Photochemical modeling of the impact of fuels andvehicles on urban ozone using auto oil program data, Environ. Sci. Technol., 30, 787-801, 1996.

EEA (European Environment Agency): COPERT 4-Computer Programme to Calculate Emissions from Road Transport, User Manual (Version 9.0), Copenhagen, Denmark, 2012.

EEA (European Environment Agency): EMAP/CORINAIR Emission Inventory Guidebook-2013, available at: http://www.eea. euopa.eu//publications/emep-eea-guidebook-2013 (last access: 21 December 2016), 2013.

Emery, C., Tai, E., and Yarwood, G.: Enhanced meteorological modeling and performance evaluation for two Texas episodes, Report to the Texas Natural Resources Conservation Commis- 
sion, prepared by ENVIRON, International Corp, Novato, CA, 2001.

Fu, J. Y., Jiang, D., and Huang, Y. H.: 1 km Grid Population Dataset of China (PopulationGrid_China), Global Change Research Data Publishing and Repository, doi:10.3974/geodb.2014.01.06.V1, 2014.

Fu, M. L., Ge, Y. S., Tan, J. W., Zeng, T., and Liang, B.: Characteristics of typical non-road machinery emissions in China by using portable emission measurement system, Sci. Total Environ., 437, 255-261, 2012.

$\mathrm{Fu}, \mathrm{Q}$. Y.: Emission inventory and the foundation mechanism of high pollution of fine particulate matters in Shanghai, $\mathrm{PhD}$ thesis, Fudan University, Shanghai, China, 2009 (in Chinese).

Fu, X., Wang, S. X., Zhao, B., Xing, J., Cheng, Z., Liu, H., and Hao, J. M.: Emission inventory of primary pollutants and chemical speciation in 2010 for the Yangtze River Delta region, China, Atmos. Environ., 70, 39-50, 2013.

Han, K. M., Lee, S., Chang, L. S., and Song, C. H.: A comparison study between CMAQ-simulated and OMI-retrieved $\mathrm{NO}_{2}$ columns over East Asia for evaluation of $\mathrm{NO}_{x}$ emission fluxes of INTEX-B, CAPSS, and REAS inventories, Atmos. Chem. Phys., 15, 1913-1938, doi:10.5194/acp-15-1913-2015, 2015.

He, K. B. (Ed.): Guidebook of Air Pollutant Emission Inventory Development for Chinese Cities, Beijing, 2015 (in Chinese).

He, L. Q., Hu, J. N., Zu, L., Song, J. J., and Chen, D.: Emission characteristics of exhaust $\mathrm{PM}_{2.5}$ and its carbonaceous components from China I to China III heavy-duty diesel vehicles, Acta Scientiae Circumstantiae, 35, 656-662, 2015 (in Chinese).

Huang, C., Chen, C. H., Li, L., Cheng, Z., Wang, H. L., Huang, H. Y., Streets, D. G., Wang, Y. J., Zhang, G. F., and Chen, Y. R.: Emission inventory of anthropogenic air pollutants and VOC species in the Yangtze River Delta region, China, Atmos. Chem. Phys., 11, 4105-4120, doi:10.5194/acp-11-4105-2011, 2011.

Huang, R. J., Zhang, Y., Bozzetti, C., Ho, K. F., Cao, J. J., Han, Y., Daellenbach, K. R., Slowik, J. G., Platt, S. M., Canonaco, F., Zotter, P., Wolf, R., Pieber, S. M., Bruns, E. A., Crippa, M., Ciarelli, G., Piazzalunga, A., Schwikowski, M., Abbaszade, G., SchnelleKreis, J., Zimmermann, R., An, Z., Szidat, S., Baltensperger, U., Haddad, I. E., and Prevot, A. S.: High secondary aerosol contribution to particulate pollution during haze events in China, Nature, 514, 218-222, 2014.

Huang, X., Song, Y., Li, M. M., Li, J. F., Huo, Q., Cai, X. H., Zhu, T., Hu, M., and Zhang, H. S.: A high-resolution ammonia emission inventory in China Global Biogeochem. Cy., 26, GB1030, doi:10.1029/2011GB004161, 2012.

Huang, Y. H., Jiang, D., and Fu, J. Y.: 1 km Grid GDP Data of China (2005, 2010) (GDPGrid_China), Global Change Research Data Publishing and Repository, doi:10.3974/geodb.2014.01.07.V1, 2014.

JSNBS (Jiangsu Bureau of Statistics): Statistical Yearbook of Jiangsu, Beijing, China Statistics Press, 2011 (in Chinese).

JSNBS (Jiangsu Bureau of Statistics): Statistical Yearbook of Jiangsu, Beijing, China Statistics Press, 2013 (in Chinese).

Kurokawa, J., Ohara, T., Morikawa, T., Hanayama, S., JanssensMaenhout, G., Fukui, T., Kawashima, K., and Akimoto, H.: Emissions of air pollutants and greenhouse gases over Asian regions during 2000-2008: Regional Emission inventory in ASia (REAS) version 2, Atmos. Chem. Phys., 13, 11019-11058, doi:10.5194/acp-13-11019-2013, 2013.
Lei, Y., Zhang, Q., Nielsen, C., and He, K. B.: An inventory of primary air pollutants and $\mathrm{CO}_{2}$ emissions from cement production in China, 1990-2020, Atmos. Environ., 45, 147-154, 2011.

Li, L., Chen, C. H., Fu, J. S., Huang, C., Streets, D. G., Huang, H. Y., Zhang, G. F., Wang, Y. J., Jang, C. J., Wang, H. L., Chen, Y. R., and Fu, J. M.: Air quality and emissions in the Yangtze River Delta, China, Atmos. Chem. Phys., 11, 16211639, doi:10.5194/acp-11-1621-2011, 2011.

Li, M., Zhang, Q., Streets, D. G., He, K. B., Cheng, Y. F., Emmons, L. K., Huo, H., Kang, S. C., Lu, Z., Shao, M., Su, H., Yu, X., and Zhang, Y.: Mapping Asian anthropogenic emissions of nonmethane volatile organic compounds to multiple chemical mechanisms, Atmos. Chem. Phys., 14, 5617-5638, doi:10.5194/acp14-5617-2014, 2014

Lin, J.-T., Martin, R. V., Boersma, K. F., Sneep, M., Stammes, P., Spurr, R., Wang, P., Van Roozendael, M., Clémer, K., and Irie, H.: Retrieving tropospheric nitrogen dioxide from the Ozone Monitoring Instrument: effects of aerosols, surface reflectance anisotropy, and vertical profile of nitrogen dioxide, Atmos. Chem. Phys., 14, 1441-1461, doi:10.5194/acp-14-1441-2014, 2014.

Mijling, B., van der A, R. J., and Zhang, Q.: Regional nitrogen oxides emission trends in East Asia observed from space, Atmos. Chem. Phys., 13, 12003-12012, doi:10.5194/acp-1312003-2013, 2013.

Ministry of Environmental Protection (MEP): China National Ambient Air Quality Standards, GB3095-2012, MEP, Beijing, China, 2012 (in Chinese).

National Bureau of Statistics (NBS): China Statistical Yearbook 2013, China Statistics Press, Beijing, 2013a (in Chinese).

National Bureau of Statistics (NBS): China Industry Economy Statistical Yearbook 2012, China Statistics Press, Beijing, 2013b (in Chinese)

National Bureau of Statistics (NBS): China Energy Statistical Yearbook 2012, China Statistics Press, Beijing, 2013c (in Chinese).

Ohara, T., Akimoto, H., Kurokawa, J., Horii, N., Yamaji, K., Yan, X., and Hayasaka, T.: An Asian emission inventory of anthropogenic emission sources for the period 1980-2020, Atmos. Chem. Phys., 7, 4419-4444, doi:10.5194/acp-7-4419-2007, 2007.

Price, C., Penner, J., and Prather, M.: $\mathrm{NO}_{x}$ from lightning, Part I Global distribution based on lightning physics, J. Geophys. Res.Atmos., 102, D5, doi:10.1029/96JD03504, 1997.

Sindelarova, K., Granier, C., Bouarar, I., Guenther, A., Tilmes, S., Stavrakou, T., Müller, J.-F., Kuhn, U., Stefani, P., and Knorr, W.: Global data set of biogenic VOC emissions calculated by the MEGAN model over the last 30 years, Atmos. Chem. Phys., 14, 9317-9341, doi:10.5194/acp-14-9317-2014, 2014.

Streets, D. G., Bond, T. C., Carmichael, G. R., Fernandes, S. D., Fu, Q., He, D., Klimont, Z., Nelson, S. M., Tsai, N. Y., Wang, M. Q., Woo, J.-H., and Yarber, K. F.: An inventory of gaseous and primary aerosol emissions in Asia in the year 2000, J. Geophys. Res., 108, 8809, doi:10.1029/2002JD003093, 2003.

Streets, D. G., Fu, J. S., Jang, C. J., Hao, J. M., He, K. B., Tang, X. Y., Zhang, Y. H., Wang, Z. F., Li, Z. P., Zhang, Q., Wang, L. T., Wang, B. Y., and Yu, C.: Air quality during the 2008 Beijing Olympic Games, Atmos. Environ., 41, 480-492, 2007.

Tang, X. L., Zhang, Y., Yi, H. H., Ma, J. Y., and Pu, L.: Development a detailed inventory framework for estimating major pol- 
lutants emissions inventory for Yunnan Province, China, Atmos. Environ., 57, 116-125, 2012.

Tian, H. Z., Liu, K. Y., Hao, J. M., Wang, Y., Gao, J. J., Qiu, P. P., and Zhu, C. Y.: Nitrogen oxides emissions from thermal power plants in China: Current status and future predictions, Environ. Sci. Technol., 47, 11350-11357, 2013.

Wang, K., Zhang, Y., Jang, C., Phillip, S., and Wang, B. Y.: Modeling intercontinental air pollution transport over the trans-Pacific region in 2001 using the Community Multi scale Air Quality modeling system, J. Geophys. Res.-Atmos., 114, D04307, doi:10.1029/2008JD010807, 2009.

Wang, L. T., Jang, C., Zhang, Y., Wang, K., Zhang, Q., Streets, D. G., Fu, C. J., Lei, Y., Schreifels, J., He, K. B., Hao, J. M., Lam, Y. F., Lin, J., Meskhidze, N., Voorhees, S., Evarts, D., and Phillips, S.: Assessment of air quality benefits from national air pollution control policies in China. Part II: Evaluation of air quality predictions and air quality benefits assessment, Atmos. Environ., 44, 3449-3457, 2010.

Wang, L. T., Wei, Z., Yang, J., Zhang, Y., Zhang, F. F., Su, J., Meng, C. C., and Zhang, Q.: The 2013 severe haze over southern Hebei, China: model evaluation, source apportionment, and policy implications, Atmos. Chem. Phys., 14, 3151-3173, doi:10.5194/acp-14-3151-2014, 2014.

Wang, Q. D., Huo, H., He, K. B., Yao, Z. L., and Zhang, Q.: Characterization of vehicle driving patterns and development of driving cycles in Chinese cities, Transport Res. D.-Tr. E., 13, 289-297, 2008.

Wang, S. X., Zhao, M., Xing, J., Wu, Y., Zhou, Y., Lei, Y., He, K. B., Fu, L. X., and Hao, J. M.: Quantifying the air pollutants emission reduction during the 2008 Olympic Games in Beijing, Environ. Sci. Technol., 44, 2490-2496, 2010.

Wang, S. X., Xing, J., Jang, C. J., Zhu, Y., Fu, J. S., and Hao, J. M.: Impact assessment of ammonia emissions on inorganic aerosols in east China using response surface modeling technique, Environ. Sci. Technol., 45, 9293-9300, 2011.

Wei, W., Wang, S. X., Chatani, S., Klimont, Z., Cofala, J., and Hao, J. M.: Emission and speciation of non-methane volatile organic compounds from anthropogenic sources in China, Atmos. Environ., 42, 4976-4988, 2008.

Xia, S. J., Zhao, Q. Y., Li, B., and Shen, G. F.: Anthropogenic source VOCs emission inventory of Jiangsu Province, Res. Environ. Sci., 27, 120-126, 2014 (in Chinese).

Xia, Y. M., Zhao, Y., and Nielsen, C. P.: The benefits of China's efforts in gaseous pollutant control indicated by the bottom-up emissions and satellite observations, Atmos. Environ., 136, 4353, 2016.

Yang, F., Tan, J., Zhao, Q., Du, Z., He, K., Ma, Y., Duan, F., Chen, G., and Zhao, Q.: Characteristics of $\mathrm{PM}_{2.5}$ speciation in representative megacities and across China, Atmos. Chem. Phys., 11, 5207-5219, doi:10.5194/acp-11-5207-2011, 2011.

Ye, S. Q., Zheng, J. Y., Pan, Y. Y., Wang, S. S., Lu, Q., and Zhong, L. J.: Marine emission inventory and its temporal and spatial characteristics in Guangdong Province, Acta Sci. Circum., 34, 537547, 2014 (in Chinese).

Yin, S. S., Zheng, J. Y., Zhang, L. J., and Zhong, L. J.: Anthropogenic ammonia emission inventory and characteristic in the Pearl River Delta region, Environ. Sci., 31, 1146-1151, 2010 (in Chinese).
Yin, S. S., Zheng, J. Y., Lu, Q., Yuan, Z. B., Huang, Z. J., Zhong, L. J., and Lin, H.: A refined 2010-based VOC emission inventory and its improvement on modeling regional ozone in the Pearl River Delta Region, China, Sci. Total Environ., 514, 426-438, 2015.

Zhang, H. L., Li, J. Y., Ying, Q., Yu, J. Z., Wu, D., Cheng, Y., He, K. B., Jiang, J. K.: Source apportionment of $\mathrm{PM}_{2.5}$ nitrate and sulfate in China using a source-oriented chemical transport model, Atmos. Environ., 62, 228-242, 2012.

Zhang, L. J., Zheng, J. Y., Yin, S. S., Peng, K., and Zhong, L. J.: Development of non-road mobile source emission inventory for the Pearl River Delta region, Environ. Sci., 31, 886-891, 2010 (in Chinese).

Zhang, Q., Streets, D. G., Carmichael, G. R., He, K. B., Huo, H., Kannari, A., Klimont, Z., Park, I. S., Reddy, S., Fu, J. S., Chen, D., Duan, L., Lei, Y., Wang, L. T., and Yao, Z. L.: Asian emissions in 2006 for the NASA INTEX-B mission, Atmos. Chem. Phys., 9, 5131-5153, doi:10.5194/acp-9-5131-2009, 2009.

Zhang, Y., Liu, P., Pun, B., and Seigneur, C.: A comprehensive performance evaluation of MM5-CMAQ for the Summer 1999 Southern Oxidants Study episode-Part I: Evaluation protocols, databases, and meteorological predictions, Atmos. Environ., 40, 4825-4838, 2006.

Zhang, Y., Wang, W., Wu, S.-Y. Wang, K., Minoura, H., and Wang, Z. F.: Impacts of updated emission inventories on source apportionment of fine particle and ozone over the southeastern U.S., Atmos. Environ., 88, 133-154, 2014.

Zhao, B., Wang, P., Ma, J. Z., Zhu, S., Pozzer, A., and Li, W.: A high-resolution emission inventory of primary pollutants for the Huabei region, China, Atmos. Chem. Phys., 12, 481-501, doi:10.5194/acp-12-481-2012, 2012.

Zhao, B., Wang, S. X., Dong, X. Y., Wang, J. D., Duan, L., Fu, X., Hao, J. M., and Fu, J. S.: Environmental effects of the recent emission changes in China: implications for particulate matter pollution and soil acidification, Environ. Res. Lett., 8, 24-31, 2013.

Zhao, Y., Wang, S. X., Duan, L., Lei, Y., Cao, P. F., and Hao, J. M.: Primary air pollutant emissions of coal-fired power plants in China: current status and future prediction, Atmos. Environ., 42, 8442-8452, 2008.

Zhao, Y., Wang, S. X., Nielsen, C. P., Li, X. H., and Hao, J. M.: Establishment of a database of emission factors for atmospheric pollutants from Chinese coal-fired power plants, Atmos. Environ., 44, 1515-1523, 2010.

Zhao, Y., Nielsen, C. P., McElroy, M. B., Zhang, L., and Zhang, J.: CO emissions in China: uncertainties and implications of improved energy efficiency and emission control, Atmos. Environ., 49, 103-113, 2012a.

Zhao, Y., Nielsen, C. P., and McElroy, M. B.: China's $\mathrm{CO}_{2}$ emissions estimated from the bottom up: Recent trends, spatial distributions, and quantification of uncertainties, Atmos. Environ., 59, 214-223, 2012b.

Zhao, Y., Zhang, J., and Nielsen, C. P.: The effects of recent control policies on trends in emissions of anthropogenic atmospheric pollutants and $\mathrm{CO}_{2}$ in China, Atmos. Chem. Phys., 13, 487-508, doi:10.5194/acp-13-487-2013, 2013.

Zhao, Y., Qiu, L. P., Xu, R. Y., Xie, F. J., Zhang, Q., Yu, Y. Y., Nielsen, C. P., Qin, H. X., Wang, H. K., Wu, X. C., Li, W. Q., and Zhang, J.: Advantages of a city-scale emission inventory for ur- 
ban air quality research and policy: the case of Nanjing, a typical industrial city in the Yangtze River Delta, China, Atmos. Chem. Phys., 15, 12623-12644, doi:10.5194/acp-15-12623-2015, 2015.

Zhao, Y., Mao, P., Zhou, Y., Yang, Y., Zhang, J., Wang, S., Dong, Y., Xie, F., Yu, Y., and Li, W.: Improved provincial emission inventory and speciation profiles of anthropogenic non-methane volatile organic compounds: a case study for Jiangsu, China, Atmos. Chem. Phys. Discuss., doi:10.5194/acp-2016-1121, in review, 2017.

Zheng, J. Y., Zhang, L. J., Che, W. W., Zheng, Z., and Yin, S. S.: A highly resolved temporal and spatial air pollutant emission inventory for the Pearl River Delta region, China and its uncertainty assessment, Atmos. Environ., 43, 5112-5122, 2009.
Zheng, J. Y., Fu, F., Li, Z. C., Wang, S. S., and Zhong, L. J.: Implementation and evaluation of uncertainty propagation using stochastic response surface method based on the CMAQ model, Acta Sci. Circum., 32, 1289-1298, 2012 (in Chinese).

Zhou, Y. and Zhao, Y.: Emissions Jiangsu China 2012, available at: http://www.airqualitynju.com/En/Data/List/Datadownload (last access: 21 December 2016), 2016. 